\title{
X-Ray Computed Tomography Examination and Comparison of Gas Hydrate Dissociation in NGHP-01 Expedition (India) and Mount Elbert (Alaska) Sediment Cores: Experimental Observations and Numerical Modeling
}

\author{
Timothy J. Kneafsey*, George J. Moridis \\ Lawrence Berkeley National Laboratory \\ *(510)486-4414, (510)486-5686 (fax), tjkneafsey@lbl.gov
}

\begin{abstract}
Natural gas from methane hydrate could provide a desireable resource. As part of a longterm investigation of producing gas from methane hydrate, lab-scale gas production tests have been performed using natural cores from India's Natural Gas Hydrate Program 01 Expedition (NGHP-01), and from the Mount Elbert Stratigraphic Well on the North Slope, of Alaska. Prior to performing the gas production tests, a number of cores from the NGHP-01 were scanned using X-ray computed tomography (CT) to examine the gas hydrate-bearing sediment structure, which guided the selection of the core for the gas production test. Disseminated gas hydrate, gas hydrate in veins, and gas hydrate in nodules were observed or inferred from the CT data. Data from numerous core segments are presented here and in the supplemental information. In our gas production test, the gas hydrate in the NGHP-01 core was dissociated by warming the core to above the stability point, and then depressurizing the sample. A preserved sample of gas hydratebearing sandstone from the Mount Elbert Test Well was dissociated by depressurization. In both tests, the internal temperature of the sample was monitored in two locations and the density changes at high spatial resolution were measured using X-ray CT scanning. Although there were indications of dissociation in the NGHP-01 core, no gas was
\end{abstract}


produced. The Mount Elbert sample contained two distinct regions having different porosity and grain size distributions. The gas hydrate dissociation occurred initially throughout the sample as a result of lowering the pressure below methane hydrate stability conditions. This initial depressurization stage in the experiment reduced the temperature to the methane hydrate equilibrium point, and the pressure was controlled so that the temperature remained above the ice point. After that, dissociation occurred from the outside into the core sample as a result of heat transfer from the controlled temperature bath surrounding the pressure vessel. Numerical modeling of the laboratory test results using TOUGH+HYDRATE yielded a gas production curve that closely matches the experimentally measured curve.

\section{Introduction}

Recent studies have concluded that naturally occurring methane hydrate (hereafter hydrate), a clathrate compound consisting of molecular water cages surrounding gas molecules (primarily methane), contains large quantities of methane in shallow sediments throughout the world's coastal margins and polar regions (Boswell et al., 2011; Milkov, 2004; Sloan et al., 1998). Each cubic meter of hydrate can hold approximately $160 \mathrm{~m}^{3}$ of natural gas at standard temperature and pressure (National Resource Council, 2004). Even though natural gas from hydrate shows great promise as an energy resource, scientific and engineering questions remain regarding producing gas from hydrates. Three methods are typically considered to produce gas from hydrate: depressurization, where the system pressure is lowered below the hydrate stability pressure; thermal stimulation, where the hydrate-bearing sediments are heated to temperatures in excess of 
the hydrate stability temperature, and the use of inhibitors such as sodium chloride or alcohols that modify the hydrate stability conditions to destabilize the hydrate (Sloan and Koh, 2008). Of these techniques, heating the hydrate-bearing sediments and injecting expensive alcohols or corrosive brines may have limited applications, and will often be impractical, particularly considering the size of reservoirs and the lack of control that can be exerted to directly apply the heat or inhibitor to the location needed. Depressurization is expected to be effective in many situations, however the hydrate-bearing sediments must be adequately confined by low permeability strata for the depressurization to be effective. Many suboceanic deposits are thought to contain hydrate in low concentration over large regions, in low permeability clays or fine-grain sediments, or in strata that are not well connected to moderate permeability zones, such that gas production is impractical (Moridis and Sloan, 2007). Known terrestrial deposits of methane hydrate are present in regions beneath the North Slope of Alaska where conditions are suitable for methane hydrate occurrence. These hydrate-bearing strata are confined by lowpermeability layers (Boswell et al., 2011), making depressurization the apparent method for production.

Several drilling and coring studies have been performed globally to examine the presence, abundance, and conditions under which gas hydrate occurs in regions such as the Nankai Trough, offshore Japan (Fujii et al, 2009), Ulleung Basin, offshore Korea (Ryu et al. 2013), Gulf of Mexico, offshore US (Ruppel et al, 2008), Hydrate Ridge, offshore US (Trehu et al, 2004), Offshore Indian Penninsula (India - NGHP-01, Collett et al., this issue), the Mackenzie Delta, Canada, (Collett et al. 1999), and the North Slope of Alaska, including the Mount Elbert Stratigraphic Test Well, US, (Hunter et al., 2011). 
Cores from two of these studies (the NGHP-01 Expedition and the Mount Elbert Stratigraphic Test Well) were studied in this work including X-ray computed tomography (CT) scanning, gas production tests, and numerical modeling of the gas production test using the Mount Elbert sample.

NGHP-O1

From 28 April, 2006 to 19 August, 2006, gas hydrate coring, drilling, and downhole logging operations were undertaken during India's National Gas Hydrate Program Expedition 01 off the Indian Peninsula and along the Andaman convergent margin to enhance understanding the geologic and geochemical controls on the occurrence of gas hydrate in these two diverse settings (Collett et al, this volume). This expedition was performed to study the spatial and temporal occurrence of gas hydrate in the offshore of India with the long-term goal of exploiting the gas hydrate as an energy source (Collett et al, 2008).

As part of the NGHP-01 study, seventeen core segments consisting of both pressurecored and non-pressure-cored samples were examined using CT while the temperature was maintained near $-196^{\circ} \mathrm{C}$ to keep the hydrate stable. To better understand gas production from the hydrate-bearing samples, a gas production test was performed using one of these samples. The sample was selected based on the CT examination of a pressure core sample that exhibited many low-density, apparent gas hydrate-bearing veins.

Mount Elbert Well 
After careful evaluation of regional seismic and well log data, the BPXA-DOE-USGS Mount Elbert Gas Hydrate Stratigraphic Test Well (Mount Elbert Well) was drilled in February 2007 (Hunter et al. 2011). This drilling and coring operation allowed for the comparison of predicted and actual subsurface geologic conditions including the presence and saturation of hydrate, provided a detailed description of the lithology, pore water chemistry, and gas composition, and retrieved hydrate-bearing cores for analysis and testing. These data, along with predictions of the expected conditions, provide an opportunity to compare predictions to as-found conditions and refine seismic prediction tools, as well as provide input information for simulating possible natural gas extraction from this region.

As part of that study and in comparison to the dissociation test on the NGHP-01 core, we performed a controlled dissociation experiment by depressurization of a preserved hydrate-bearing sample from the Mount Elbert Well, and have also simulated this process using TOUGH+HYDRATE (Moridis et al., 2008). The TOUGH+HYDRATE code was developed to evaluate hydrate-related questions, including the production of gas from gas hydrates and methane release resulting from climate change. Comparison of simulator predictions to analytical solutions, field data, and laboratory data is needed to build confidence in the model.

\section{X-ray CT Examination of NGHP-01 Cores}

\section{Method}

Seventeen core samples preserved in liquid nitrogen were scanned using a modified 
Seimens Somatom HiQ third-generation medical computed tomography (CT) scanner. $\mathrm{X}$-ray CT scanning is a nondestructive method that provides the three-dimensional density distribution of the scanned samples. Knowledge of the density distribution, along with other medium properties allows one to infer the distribution of hydrate in the sample. In many cases, particularly for samples contained in X-ray transparent containers or liners, CT scanning can be performed without any sample disturbance. For the NGHP-01 samples preserved in liquid nitrogen, no additional sample disturbance occurred during scanning, as the samples were scanned while in liquid nitrogen.

\section{Scanning Method}

The approximately $66 \mathrm{~mm}$ diameter cores were removed from the shipping dewars and placed in a Styrofoam cooler containing liquid nitrogen (LN). Two cores were scanned side-by-side at one time. Both cores were initially submerged in LN. Following scanning, the cores were returned to the dewars containing LN. The scanning parameters were selected to optimize scanning time, while providing reasonable information on core composition. The resolution selected for the scanning was 373 microns $\mathrm{x} 373$ microns $\mathrm{x}$ 3000 microns in the axial direction. The images were calibrated to density by scanning a variety of uniform materials with known density, and applying a linear calibration relationship constructed from the densities of materials from water to aluminum. Beamhardening artifacts are present on the images. These artifacts result from the use of a polychromatic X-ray source, because lower energy X-rays are more strongly absorbed in the outer regions of a core giving it a brighter (higher density) appearance. This effect was not corrected for in the images. 


\section{Selected CT Scanning Results}

Density distributions for all cores examined are contained in the supplemental information. Table 1 presents descriptions and CT results of a selected number of cores. In the images in Table 1, the density distribution of each core (in $\mathrm{g} / \mathrm{cm}^{3}$ ) is depicted as a sequential series of $3 \mathrm{~mm}$ thick disks (similar to a stack of coins) presented from left to right and top to bottom. In the cores, hydrate is present in veins (purple veins in Table 1g), nodules (large dark region in Table 1b), and disseminated (see change in density from the center of the core outward as a result of hydrate dissociation at the outer radii in Table 1f). These observations are consistent with results of shipboard core examinations (Collett et al. 2008). Cores retrieved as pressure cores typically had very small disturbed regions at the outer radii (compare Table 1g - pressure-cored, to Table 1f - nonpressurecored which shows a large region near the outer radius as having a significantly different density than the center). Disseminated hydrate is inferred by lower-density outer radii of unfractured non-pressure cores; hydrate nodes and hydrate-filled veins are identified by density. It is interesting that the orientation of the veins tends to rotate in some samples

(eg. Table 1g), indicating that the sediment containing the hydrate was not stiff enough to resist the shear force exerted by the twisting core barrel. One sample (Table 1c) had regions with densities exceeding $3 \mathrm{~g} / \mathrm{cm}^{3}$, likely pyrite-rich as this dense mineral is present at locations in the sediment column (Collett et al., 2008).

\section{Hydrate Dissociation Tests}

\section{Method}

To keep samples cold enough to maintain hydrate stability, the samples were frequently 
submersed in LN during machining which was performed to adjust the diameter, length, and to insert the thermocouples. Machining was performed to allow testing of as large a sample as possible. Following machining and resubmersion in $\mathrm{LN}$, samples were removed from the LN, and rapidly placed in an elastomer sleeve between two PVC endpieces (Figure 1). The assembly was then sealed into a chilled propylene glycol bath inside an X-ray transparent pressure vessel, and rapidly connected to the pressure control system before the sample had experienced significant warming.

\section{NGHP-01 Sample Description}

The sample used in our test was an LN-preserved pressure core from Hole 21A (water depth 1049 m, BSR 160 mbsf, sample depth 59 mbsf, characterized by veins in clay/silt sediments from an apparent fractured reservoir) was a dark sample with noticeable white veins. The initial hydrate content of the sample was not known, but presumed to be high relative to other NGHP-01 samples because of the abundance of lower-density veins that were assumed to be hydrate-bearing (more on hydrate saturation in the discussion section of this paper). It was CT scanned (Figure 2a) soon after placement in the pressure vessel and establishment of confining and pore pressure conditions, with the CT images showing more veins than were visible by eye. A few $\mathrm{mL}$ of gas at room temperature and pressure were observed to leak from the vessel while rapidly connecting the sample to the system. The sample was slowly warmed, and prior to complete thawing (about 4 hours, CT scan Figure 2b), the pressure in the inlet and outlet pumps was increased to insure that hydrate was stable. The very low dissipation of differential pressure across the core from the stepwise pressurization using two pumps reached higher than a hundred psi 
indicating very low gas permeability. Depressurization would be the method of choice for a permeable medium, however the low permeability indicated that dissociation by depressurization may not be effective, thus dissociation by thermal stimulation was performed (Moridis et al, 2009). The sample was slowly warmed to the equilibrium point and after 22 hours the temperature was allowed to exceed the equilibrium temperature. No gas was collected, within the errors of the measurements. The collection pumps have a resolution of $0.01 \mathrm{~mL}$, however temperature variation in the room could cause volume changes in the pumps and lines on the order of $\mathrm{mL}$. Upon opening the pump following the test, gassy water was produced indicating the presence of dissolved gas, presumed to be methane.

Figure $2 b$ shows an image of the thawed sample. The effective stress applied (confining pressure - pore pressure) was about $70 \mathrm{psi}$, which would be similar but slightly higher than the effective stress of the natural sample. When the sample thawed under these conditions, its shape changed dramatically. The shape appears to be influenced by the presence of the hydrate veins, which as presumably stiffer components, failed sometime after the rest of the sample. Also note, the density of the sample increased from Figure 2a to Figure $2 b$ as a result of the compaction. This is attributed to the effect of freezing and thawing on the clays in the sample.

The CT images in Figure 2c indicate changes that occurred between the thawed sample and the completion of the dissociation. The red indicates an increase in density, and could be caused by low-density hydrate being replaced by higher density mineral, and the blue indicates a decrease in density, which could be caused by hydrate dissociation and the presence of gas. These changes are attributed to hydrate dissociation, however the 
amount of gas produced from the system was within the errors of the measurements and computations. No modeling was performed since we were unable to produce gas from the unconsolidated very fine sediments.

\section{Mount Elbert Sample Description}

The core sample having two distinct regions (HYPV4, from 663.89 to $664.14 \mathrm{~m}$ depth; 2178.12 to $2178.92 \mathrm{ft}$ depth) was collected for this study during the coring performed in the Mount Elbert Stratigraphic Test Well during February 2007. A description of the coring operations and associated core samples are included in Hunter et al, (2011), along with a set of CT data for a number of Mount Elbert cores (Kneafsey et al. 2011). Coring was performed using a chilled custom oil-based mud to aid in sample preservation, however pressure-coring techniques were not used. The sample studied in our test was one of several that were retrieved, cut to 10-inch length, scraped clean, wrapped in aluminum foil, and placed in pressure vessels (Parr Instruments, Moline, IL) which were pressurized to $5.52 \mathrm{MPa}$ (800 psi) with $99.99 \%$ pure methane gas. The vessels were kept at temperatures ranging from $-40^{\circ} \mathrm{C}$ to $-4^{\circ} \mathrm{C}$. Prior to shipping from the well site, the vessels were inspected and it was noted that pressures had decreased (presumably from cooling, small gas leaks in the vessel seals or valves, or by hydrate formation, as the samples were maintained at pressures well within the hydrate stability zone), and the vessels were repressurized to $6.20 \mathrm{MPa}$ (900 psi) then shipped overland to Anchorage, Alaska. Temperatures during transportation in late February ranged from -40 to -10 degrees C. After arrival in Anchorage, the pressurized core samples were stored in a refrigerated container maintained at $-7^{\circ} \mathrm{C}$. Prior to further shipping, the pressure vessels, 
which were again noted to be below the initial pressure, were rapidly depressurized (in about 1 minute), the samples removed, labeled, placed into cloth bags and immersed in LN (taking 3-6 minutes). Further description of the samples and primary and secondary hydrate in the cores is presented in Kneafsey et al. (2011).

\section{Mount Elbert Gas Production Experiment Description}

The core sample was machined to fit the custom sleeve similar to the NGHP-01 core by intermittently removing it from $\mathrm{LN}$, rapidly performing a machining operation (e.g. briefly sanding a side or drilling a hole) and returning it to the LN to cool it prior to the next machining step. When machining, the sample was set on an insulator, rather than the steel tool tables to reduce sample warming. When machining was completed and the sample was chilled to $-196^{\circ} \mathrm{C}$, it was inserted into the custom nitrile sleeve, which had been mounted to a PVC endpiece having a thermocouple extending through the center of the endpiecs. The opposing PVC endpiece with a thermocouple extending through its center was rapidly inserted and attached, and the assembly was sealed within the pressure vessel filled with a water/propylene glycol mixture chilled to about $-30^{\circ} \mathrm{C}$. Immediately, confining pressure was applied and the pore pressure was controlled. The temperature of the pressure vessel was controlled by flowing chilled propylene glycol/water through the PVC jacket surrounding the aluminum vessel. A schematic of the system is shown in Figure 1 and three cross sections of the sample are shown in Figure 3 to show the structure of the PVC endpiece, and the locations of the thermocouples. 
As the core warmed from $-196^{\circ} \mathrm{C}$, the confining pressure was increased so that it always exceeded the pore pressure of the sample. The sample was slowly warmed and equilibrated at about $570 \mathrm{psig}$ and $4.27^{\circ} \mathrm{C}$. While the temperature was still below $0^{\circ} \mathrm{C}$, the assembly was CT scanned. CT scanning revealed that the sample spanned across two strata having different porosities (Figure 4a). Subsequent analysis of subsamples revealed that each part of the core had a different grain size distribution (Table 2), but similar mineralogy (Figure 4b) [Rees et al., 2011].

The inlet and outlet of the sample vessel were connected to high-pressure syringe pumps (Teledyne Isco, Lincoln NE) containing methane. Prior to the depressurization test, we attempted to flow gas through the sample in order to assess its effective permeability. Under reasonable conditions, no gas flowed through the sample, thus the effective permeability was quite low. After resetting the pressure to $570 \mathrm{psi}$, the core was sealed. The lines between the control valves and the pumps on both sides of the core and the high-pressure syringe pumps were set to maintain 445 psig, and Pump 2 was isolated from the system at valve V2. To depressurize the sample, valves V1 and V3 were opened.

\section{The Numerical Models and Simulation Approach}

\section{The Numerical Simulation Code}

We used the serial and parallel versions of the TOUGH+HYDRATE simulator (Moridis et al., 2008; Zhang et al., 2008) to conduct the numerical studies in this paper. This code (hereafter referred to as $\mathrm{T}+\mathrm{H}$ ) can model all the known processes involved in the 
response of the $\mathrm{CH}_{4}+\mathrm{H}_{2} \mathrm{O}$ system to pressure and temperature changes in the pores and fractures of complex geologic media, including the flow of fluids and heat, the thermophysical properties of reservoir fluids, thermodynamic changes and phase behavior, and the non-isothermal chemical reaction of $\mathrm{CH}_{4}$-hydrate formation and/or dissociation, which can be described by either an equilibrium or a kinetic model (Kim et al., 1998; Clarke and Bishnoi, 2001; Kowalsky and Moridis, 2007). T+H is a compositional simulator, and its formulation accounts for heat and up to four mass components (i.e., $\mathrm{H}_{2} \mathrm{O}, \mathrm{CH}_{4}, \mathrm{CH}_{4}$-hydrate, and water-soluble inhibitors such as salts or alcohols) that are partitioned among four possible phases: gas, aqueous liquid, ice, and hydrate. The $\mathrm{T}+\mathrm{H}$ code can describe all the 15 possible thermodynamic states (phase combinations) of the $\mathrm{CH}_{4}+\mathrm{H}_{2} \mathrm{O}$ system and any combination of the three main methods of hydrate dissociation: depressurization, thermal stimulation, and the effect of inhibitors.

\section{System geometry and domain discretization.}

The system modelled in this study is the experimental core assembly described above. The dimensions of the system and of its various components (hydrate-bearing core, Buna sleeve, PVC end-caps, confining and heat-exchanging fluid, and the aluminum vessel) were the same as the experiment system. Note that the simulation domain was somewhat trimmed from the full system in that it was limited to (a) the part of the assembly between the outer edges of the PVC end-plates along the length of the core, and to the outer diameter of the aluminum vessel. This limited domain was considered adequate for an accurate representation of the system behavior because (a) the temperature of the sample at the two PVC end-caps was treated as an input (as obtained from direct measurements), 
and (b) the temperature of the bath surrounding the aluminum vessel was known (also from direct measurements). Thus, imposing these two temperatures as boundary temperatures prevented erroneous computations that could have been caused by an inaccurate heat balance during the dissociation process.

For maximum accuracy, very fine grids were used in the simulation of production. Because gravity cannot be ignored due to the release of water during dissociation, a three-dimensional Cartesian grid was used to represent the simulated domain. Fortunately, only half of the domain needed to be simulated because of symmetry about the vertical (z-) plane. The 7.97 inch $(=202.5 \mathrm{~mm})$ of the core and PVC end-caps along the length of the core (x-direction) were subdivided into 83 segments, of which 81 of $\Delta x$ $=2.5 \mathrm{~mm}$ in length, and the two outermost ones (representing the variable-temperature boundaries of the confining fluid) with $\Delta \mathrm{x}=1 \mathrm{~mm}$. Along the z-axis, the 3.5 inch $(=88.9$ $\mathrm{mm}$ ) diameter of the domain was discretized into 52 subdivisions, of which:

-The outermost one corresponded to the liquid bath boundary, with a $\Delta \mathrm{z}=1 \mathrm{~mm}$;

-The next two cells (corresponding to the outer layers of the outer diameter of the aluminum vessel) had a $\Delta \mathrm{z}=1.18 \mathrm{~mm}$;

-The remainder of the metal vessel thickness was represented by 4 cells/layers of $\Delta z=1$ $\mathrm{mm}$

-The inside of the vessel including the hydrate-bearing core from $\mathrm{z}=1.5$ " to $\mathrm{z}=0$ " (= $38.1 \mathrm{~mm}$ in total) was discretized into a subdivision with $\Delta \mathrm{z}=2.1 \mathrm{~mm}$ and 18 with $\Delta \mathrm{z}=$ $2.0 \mathrm{~mm}$;

-The discretization of the lower half of the cylindrical assembly (i.e., from $z=0$ " to $z=-$ 
1.5”) was a mirror image of that of the upper half.

The discretization along the $y$-axis was the same as that in the upper (or lower) half of the z-direction. Because the Cartesian discretization described above was used to describe a cylindrical domain, a small program was written to (a) eliminate all cells outside the outermost cylindrical boundaries of the system, (b) adjust the surface area at the intersection/contact of different materials and subdomains to ensure correct heat exchange, and (c) adjust the boundary gridblock volumes to correctly reflect the actual system volume. Thus, the total number of gridblocks were reduced from $83 \times 52 \times 26=$ 112,216 in $(\mathrm{x}, \mathrm{y}, \mathrm{z})$ to 88,134 , resulting in a system of 264,402 equations during the analysis of the hydrate dissociation problem.

\section{System properties, initial and boundary conditions.}

The initial and boundary conditions (pressure and temperature) were as described above and presented in Table 3. Of the other properties, the intrinsic permeability $\mathrm{k}=10^{-12} \mathrm{~m}^{2}$ (= 1 darcy) was as determined from the history matching of data from an earlier field test of depressurization-induced hydrate dissociation at the Mt. Elbert site from which the core originated (Anderson et al., 2008; Moridis et al. 2010). This number is in reasonable agreement with the permeability calculated from the grain size distribution (Rees et al., 2011) using the Kozeny-Carman equation. This number is reasonable in spite of the initially observed low effective permeability because that value accounted for hydrate in the porespace. The initial porosities $\Phi$ and hydrate saturations $S_{H}$ of the two regions of the core (Table 2, Figure 4) were as determined from the CT scan analysis. The relative 
permeability relationships and the corresponding parameters were based on data obtained from history matching of the results of field test that had been conducted at the site (Anderson et al., 2008), and are shown in Table 3. The capillary pressure relationships and parameters were determined from the particle size analysis of porous media samples from the deeper (but similar) C unit (White, 2008) and porosity was consistent with the $\Phi$ of the formation (Table 2). Note that the same relative permeability and capillary pressure expressions were assumed to apply to both regions of the core. Finally, the thermal properties of the various components and subdomains of the system (Table 3) were obtained from various publications.

\section{Results}

\section{Mount Elbert Gas Production Experiment Results}

The temperatures at three locations (two along the center axis of the core near the ends, and one in the confining fluid) and the differential pressure across the core are presented in Figure 5 for the depressurization test. Upon opening valve V1 to begin the depressurization, the pressure on that side (for reference - left side) of the core dropped rapidly to the dissociation pressure (445 psig). The pressure on the opposite side (for reference - right side) increased towards the original system pressure as gas from the sample filled the tubing that had initially been depressurized to $445 \mathrm{psig}$, and then soon after began dropping towards the dissociation pressure. This resulted in a high pressure differential across the core (up to 95 psi) initially, which dropped over three minutes to 
less than $20 \mathrm{psi}$, which is within the range of the differential pressure transducer (Rosemount, Chanhassen, MN) connected across the inlet and outlet.

The temperatures at both ends of the core dropped rapidly in response to the depressurization. T1 (left side, near Pump 1 side in Figure 1) dropped immediately, and T2 (right side) lagged behind by several hundred seconds (Figure 5). This temperature drop occurred because methane hydrate dissociation is endothermic, and the dissociation was extracting energy from the system. The temperature of the confining fluid immediately outside the sleeve surrounding the sample (yet isolated from the constant temperature bath by the pressure vessel wall) declined as well with an additional lag in response to the cooling of the sample. The temperature of the cooling bath, although monitored at a location that is remote from the vessel, did not change as a result of the cooling, indicating that the temperature of the fluid in the temperature control jacket was relatively stable over the test. T1 began to rise towards the controlled temperature indicating depletion of hydrate after about 5100 seconds, and the temperature at the right side $\mathrm{T} 2$ began to rise towards the control temperature after about 6700 seconds.

The differential pressure, along with the gas production rate, could be used to estimate the effective permeability of the core. Hydrate dissociation releases water and gas, but water is preferentially retained by the water-wet mineral core. Since most of the fluid produced (leaving the core) from the sample was gas (there may have been a small amount of liquid produced), the flow rate and differential pressure provides information that could be used to compute the gas relative permeability, however this would be 
subject to some assumptions. The largest assumption is that the sample has a homogeneous composition. Preferential flow paths would likely occur at the outer radii of the sample where heat transfer is highest resulting in more rapid dissociation. This would certainly affect the computation. Indeed, we see such a change in composition in Figure 6. High differential pressure is indicative of low effective permeability. The measured differential pressure was noisy over the first 10,000 seconds, corresponding to the time when the temperature at the right side began to rapidly approach the control temperature. This noisy differential pressure likely results from dissociating gas forming in pockets of capillary-held water until sufficient gas is produced to break through the capillary-held water (bubbles bursting). The smooth differential pressure decline that occurred following the noisy portion indicates that residual methane gas from dissociation and dissolution slowly leaked through the porespace.

The volume of fluids (primarily gas and some water) produced was measured at the highpressure syringe pump. The temperature of the pump was measured using a type $\mathrm{T}$ thermocouple to allow computation of the quantity (moles) of gas. The number of moles was computed using density values from NIST (Lemmon et al., 2005) based on measured temperatures and pressures is shown in Figure 7.

X-ray CT scans of 10 evenly spaced locations along the core sample were taken approximately every ten minutes (600 seconds) during the depressurization test. The CT scans provide a spatially resolved measure of the sample density at approximately 4 million locations in the sample $(\sim 78,500$ - 195 x $195 \times 3000$ micron voxels per slice, 51 
slices). Changes in the density at a location arise from 1) changes in phase occupancy within the pore space (hydrate, gas, water), 2) gas evolution from hydrate (when the gas leaves the system resulting in a decrease in mass), 3) water leaving the system, and 4) solid mineral grains rearranging or leaving the system. With few exceptions, the mineral grains were reasonably well cemented and held in place over the duration of the test by the combined cement and confining stress, thus changes in density from this are not considered. The other three processes could have happened during the test. Figure 6 shows the initial sample density and the changes in density at the 3 locations over the first 207 minutes $(12,420 \mathrm{~s})$ of the test. Locations 1 and 5 in the figure are from the lower porosity left side of the core, and Locations 10 is from the higher porosity right side.

\section{History matching results}

The $\phi$ and $\mathrm{S}_{\mathrm{H}}$ of the two regions were treated as perturbation parameters (i.e., four in total) that were determined from the history matching process as the ones minimizing the differences between observations and numerical predictions. Given the relatively large number of the perturbation parameters, the values of all other parameters and variables were fixed in the course of the optimization process.

Figure 8 shows the comparison between the measured and predicted mass of collected gas during the dissociation experiment. The match between the two data sets is very good, and the excellent agreement is attributed (at least partly) to both the experimental component of this study and the earlier studies (Anderson et al., 2008; Moridis et al., 2010) that provided good estimates of a large number of the properties and parameters 
used in the history-matching study, thus minimizing the number of perturbation parameters and enhancing the history-matching process. The optimized perturbation parameters were $\phi=0.34$ and $S_{H}=0.152$ in Region 1 of the core, and $\phi=0.37$ and $S_{H}=$ 0.270 in Region 2.

\section{Discussion}

\section{NGHP-01 Test}

Our hypotheses for the NGHP-01 core sample were that 1) reestablishing the natural conditions of the core would result in a cylindrical core under a reasonable effective stress, 2) gas released from hydrate dissociation would flow through weaker regions of the sample towards the end and be produced, and 3) the hydrate-filled veins would close when the hydrate was gone.

We assumed that the veins that are observable in the CT scans were hydrate-rich, and that the white veins that were observed prior to the test but not after the test were hydratefilled. This assumption is based on core descriptions (Collett et al., 2008). The cores were handled very carefully prior to and after receiving them. There were events that could have lowered the hydrate presence in the sample including depressurization and freezing, and machining even under very cold conditions. It is possible that some hydrate dissociated to ice during these steps in spite of precautions. We proceeded with our test based on the assumption that hydrate was present in the veins and can offer anecdotal evidence of that presence, but we were not able to quantify the amount of gas hydrate.

Reestablishing the natural conditions resulted in severe changes in the core. Freezing and thawing of clayey sediments is known to reduce its strength [Leroueil et al., 1991]. This 
strength reduction was not accounted for in the test setup. From the CT scan data, it appears that the presence of hydrate veins affected the sample mechanical failure. The shape of the failed sample protrudes somewhat in the direction of prominent hydratebearing veins. This matrix failure upon melting but not when the sample is perturbed through the equilibrium point, indicates that hydrate was not dominantly present in the matrix, as the matrix would not have failed upon ice melting if little ice were present. This is conceptually in agreement with the hydrate structures presented in Dai et al, (2012).

Upon melting under the influence of the effective stress, the formerly open veins disappeared. This was likely the result of compacting the fine sediment into void space and near the hydrate in the veins. Unlike consolidated rock, this sediment hosting the hydrate flowed under stress. This flow closed the formerly weak pathways and limited potential gas mobility. Conditions under which such released gas could move grains and flow has been studied by others (eg. Jain and Juanes, 2009; Jung et al., 2012). Changes occurred in the sample over the dissociation period indicated by further compaction in hydrate-bearing veins (eg. red band in slices 38 to 43 in Figure 2c.). No obvious gas flow pathways existed following the test. Careful examination of the final set of CT scans shows a few locations in some slices that are low-density, however the density exceeds that of water.

\section{Mount Elbert Test}

Our hypotheses for the Mount Elbert test were that 1) initial dissociation would occur from heat present in the system until the equilibrium temperature was attained, 2) hydrate 
would dissociate from the outside-into the core as a result of heat transfer, and 3) hydrate dissociation would be preferential on the outlet (left) side of the sample due to its proximity to the outlet.

\section{Pressure, Differential Pressure, Temperature}

Early in the dissociation, the temperature in the sample decreased to about $2.0^{\circ} \mathrm{C}$ at the two core measurement locations (2.0 and $2.1^{\circ} \mathrm{C}$ at $\mathrm{T} 1$ and $\mathrm{T} 2$ respectively) (Figure 5). These temperatures are consistent with methane hydrate dissociation at the different pressures at these two locations. As expected, the temperature of the confining fluid declined to a value between the bath temperature and the sample temperature. T1, closer to the fluid outlet (left) end at lower pressure, was cooler, and the dissociation near T1 ended earlier than the dissociation near T2 at the right side of the system. This was expected from such a system because of the pressure gradient across the core. The fluid outlet side (at lower pressure and larger driving force) would be expected to dissociate more rapidly than the distant side at higher pressure. The shape of the temperature curves is unusual in that when the dissociation near the thermocouples ended, the temperature rapidly increased for a short time, then the increase was moderated prior to a final rapid increase in temperature. In tests on other gas hydrate samples, temperatures more smoothly approached the control temperature once the dissociation near the thermocouple was complete (Kneafsey et al., 2007; Kneafsey et al., 2009). This nonuniform increase may result from the sample geometry and the thermocouple location. The thermocouple was placed to give an indication of the temperature inside the sample. Because the dissociation was caused by depressurization and the effective permeability of the sample 
was low, the oversized hole drilled for the thermocouple was initially a dissociation surface and later a significant gas flow pathway in the sample. The later moderation of the temperature rise was likely due to the continuing dissociation of hydrate axially inward from the thermocouple. This is supported by the fact that the initial temperature rise at $\mathrm{T} 2$ is at about 7,000 seconds, whereas the gas production levels off at about 10,000 seconds.

\section{Gas Produced}

The response upon the initiation of depressurization was a rapid collection of fluid (mostly gas) over the first 300 seconds. This was due to gas expansion in the sample and some dissociation as indicated by the immediate temperature decline. A high effective permeability would have allowed the gas to rapidly expand and be collected, however this took some time because the effective permeability was so low. During the initial depressurization, gas production is not dependent on heat transfer from outside the sample, but rather on heat contained in the system components (hydrate, water, and mineral grains) and the sample rapidly cooled to the equilibrium temperature at the prevailing pressure. Following the initial depressurization, heat transfer occurs from the outside into the sample. This results in a system that is heat-transfer controlled and yields

a decreasing rate of dissociation because heat must be transferred through a growing layer of hydrate-depleted porous media.

$X$-ray $C T$ 
We expected to see 1) initial dissociation (indicated by a slight density decrease) throughout the sample resulting from hydrate dissociation from heat contained in the sample, 2) a hydrate dissociation front that moved radially inward over time resulting from heat transfer from the temperature controlled outer boundary, and 3) faster dissociation at the lower pressure end. In Figure 6 we see a slight density decrease over the entire core sample at 600 seconds (slight blue color), but we also see a larger density decrease at the outer radii of the core from heat transfer from the confining fluid. The temperature of the confining fluid began to drop very soon (about 40 seconds) after the depressurization began, indicating heat is being transferred to the sample at that time. We were not able to capture the initial dissociation by itself by CT as indicated by the temperature and gas production data shown in Figures 5 and 7, and our first scan at 600 seconds shows a combination of initial dissociation throughout the core and thermally induced dissociation at the outer radii of the core. If we examine Slice 5 over the duration of the test, we clearly see an inwardly moving dissociation front. The less dense (blue) outer layer grows in size throughout the test. This behavior is consistent to some extent over the entire core. The behavior at Location 10 (right end) is somewhat different in that initially the dissociation proceeded radially, but then more uniformly across the profile. Heat transfer to the core through the PVC endcaps also occurred during this test although the thermal conductance of the thick PVC is lower than that for the much thinner nitrile sleeve. 


\section{Conclusions}

Methane hydrate samples from India's NGHP-01 were scanned by X-ray computed tomography. Hydrate veins, nodules, and disseminated hydrate were observed or inferred from the data. A gas production test was performed on one sample having multiple lowdensity veins assumed to contain hydrate in a clay/silt sediment following sample preparation under cold conditions. Changes occurred in the sample resulting from mechanical failure of the sample upon warming through the ice point, with hydrate possibly partially stabilizing parts of the sample, and further mechanical changes in the sample occurred when the temperature was elevated so that methane hydrate dissociation would occur. An insignificant volume of gas was produced in the test of the NGHP-01 sample, within the errors of the measurements. Predicted gas flow pathways disappeared as the result of the sample mechanical failure, and gas mobility was restricted by the fine medium.

A preserved sample of hydrate-bearing sandstone from the Mount Elbert Test Well was dissociated by depressurization while monitoring the internal temperature of the sample in two locations and the density changes at high spatial resolution using $\mathrm{x}$-ray CT scanning. Hydrate dissociation in the Mount Elbert core occurred primarily as hypothesized; initially throughout the sample as a result of lowering the pressure below the stability pressure, and then from the outside into the core as a result of heat transfer. Numerical modeling of the test yielded a gas production curve that closely follows the experimentally measured curve.

These results lead to the conclusion that gas production from hydrate will be much easier from hydrate-bearing sands than clays. The mechanical strength of the sands, although 
affected by the loss of hydrate, is likely to maintain significant permeability allowing further gas production. This is not the case in the very deformable clay reservoirs. As the hydrate dissociates, the clay will become even more deformed as the hydrate that formerly supported the medium is removed. Inducing gas flow to a well depends on being able to induce a pressure gradient causing gas flow into the formation. This does not appear to be feasible in these types of sediments. Currently there is no feasible method for producing gas from clay-rich gas hydrate systems. Devising such a method is a challenge that may keep this hydrate as a higher-hanging fruit for some time.

\section{Acknowledgements}

The authors wish to thank those that contributed to the success of the National Gas Hydrate Program Expedition 01 (NGHP-01). NGHP-01 was planned and managed through collaboration between the Directorate General of Hydrocarbons (DGH) under the Ministry of Petroleum and Natural Gas (India), the U.S. Geological Survey (USGS), and the Consortium for Scientific Methane Hydrate Investigations (CSMHI) led by Overseas Drilling Limited (ODL) and FUGRO McClelland Marine Geosciences (FUGRO). The platform for the drilling operation was the research drill ship JOIDES Resolution, operated by ODL. Much of the drilling/coring equipment used was provided by the Integrated Ocean Drilling Program (IODP) through a loan agreement with the US National Science Foundation. Wireline pressure coring systems and supporting laboratories were provided by IODP/Texas A\&M University (TAMU), FUGRO, USGS, U.S. Department of Energy (USDOE) and HYACINTH/GeoTek. Downhole logging operational and technical support was provided by Lamont-Doherty Earth Observatory (LDEO) of Columbia University. The financial support for the NGHP-01, from the Oil Industry Development Board, Oil and Natural Gas Corporation Ltd., GAIL (India) Ltd. and Oil India Ltd. is gratefully acknowledged. We also acknowledge the support extended by all the participating organizations of the NGHP-01: MoP\&NG, DGH, ONGC, GAIL, OIL, NIO, NIOT, and RIL. The authors also wish to acknowledge the many people, particularly William Winters of the USGS whose diligent efforts in both the NGHP-01 and Mount Elbert Projects made it possible to collect the samples discussed in this paper. The authors wish to thank the two anonymous reviewers and Tim Collett for critical reviews and comments improving this paper. This work was supported by the Assistant Secretary for Fossil Energy, Office of Oil and Natural Gas, through the National Energy Technology Laboratory, of the U.S. Department of Energy under 
Contract No. DE-AC02-05CH11231. Grain size distributions and mineralogy courtesy of Kyle Littlefield and Kelly Rose of the NETL.

\section{References}

Anderson, B.J. et al., 2008. Analysis of Modular Dynamic Formation Test Results From the Mount Elbert-01 Stratigraphic Test Well, Milne Point Unit, North Slope, Alaska, 6th International Conference on Gas Hydrates, Vancouver, British Columbia, Canada.

Boswell, R. et al., 2011. Geologic controls on gas hydrate occurrence in the Mount Elbert prospect, Alaska North Slope. Marine and Petroleum Geology, 28(2): 589-607.

Clarke, M. and Bishnoi, P.R., 2000. Determination of the intrinsic rate of ethane gas hydrate decomposition. Chemical Engineering Science, 55(21): 4869-4883.

Collett, T. et al., 2008. Indian national gas hydrate program expedition 01 initial reports: Expedition 01 of the Indian National Gas Hydrate Program from Mumbai, India to Chennai, India; Sites NGHP-01-01 through NGHP-01-21, April 2006 - August 2006, Directorate General of Hydrocarbons, Ministry of Petroleum and Natural Gas (India), Noida, India.

Collett, T.S. et al., 1999. Detailed evaluation of gas hydrate reservoir properties using JAPEX/JNOC/GSC Mallik 2L-38 gas hydrate research well downhole well-log displays. In: S.R. Dallimore, T. Uchida and T.S. Collett (Editors). Geological Survey of Canada Bulletin, 544, pp. pp. 295-311.

Collett, T.S., et al., (this volume), Scientific Results of the National Gas Hydrate Program Expedition.

Dai, S., Santamarina, J.C., Waite, W.F. and Kneafsey, T.J., 2012. Hydrate morphology: Physical properties of sands with patchy hydrate saturation. Journal of Geophysical Research: Solid Earth, 117(B11): B11205.

Fujii, T. et al., 2009. Methane-hydrate occurrence and saturation confirmed from core samples, eastern Nankai Trough, Japan. In: T. Collett, A. Johnson, C. Knapp and R. Boswell (Editors), Natural gas hydrates-Energy resource potential and associated geologic hazards: AAPG Memoir 89, pp. 385-400.

Hunter, R.B. et al., 2011. Mount Elbert Gas Hydrate Stratigraphic Test Well, Alaska North Slope: Overview of scientific and technical program. Marine and Petroleum Geology, 28(2): 295-310.

Jain, A.K. and Juanes, R., 2009. Preferential Mode of gas invasion in sediments: Grainscale mechanistic model of coupled multiphase fluid flow and sediment mechanics. Journal of Geophysical Research: Solid Earth, 114(B8): B08101.

Jung, J.W. et al., 2012. Gas Production from Hydrate-Bearing Sediments: The Role of Fine Particles. Energy \& Fuels, 26(1): 480-487.

Kim, H.C., Bishnoi, P.R., Heidemann, R.A. and Rizvi, S.S.H., 1987. Kinetics of methane hydrate decomposition. Chemical Engineering Science, 42(7): 1645-1653.

Kneafsey, T.J. et al., 2011. Examination of core samples from the Mount Elbert Gas Hydrate Stratigraphic Test Well, Alaska North Slope: Effects of retrieval and preservation. Marine and Petroleum Geology, 28(2): 381-393.

Kneafsey, T.J., Seol, Y., Moridis, G.J., Tomutsa, L. and Freifeld, B.M., 2009. Laboratory measurements on core-scale sediment and hydrate samples to predict reservoir 
behavior. In: T. Collett, A. Johnson, C. Knapp and R. Boswell (Editors), Natural gas hydrates-Energy resource potential and associated geologic hazards, pp. $705-713$.

Kneafsey, T.J. et al., 2007. Methane Hydrate Formation and Dissociation in a Core-Scale Partially Saturated Sand Sample. Journal of Petroleum Science and Engineering, 56: 108-126.

Kowalsky, M.B. and Moridis, G.J., 2007. Comparison of kinetic and equilibrium reaction models in simulating gas hydrate behavior in porous media. Energy Conversion and Management, 48(6): 1850-1863.

Lemmon, E.W., McLinden, M.O. and Friend, D.G., 2005. Thermophysical Properties of Fluid Systems - NIST Chemistry WebBook, NIST Standard Reference Database Number 69, http://webbook.nist.gov. National Institute of Standards and Technology.

Leroueil, S., Tardif, J., Roy, M., Rochelle, P.L. and Konrad, J.M., 1991. Effects of frost on the mechanical behaviour of Champlain Sea clays. Canadian Geotechnical Journal, 28(5): 690-697.

Milkov, A.V., 2004. Global estimates of hydrate-bound gas in marine sediments: how much is really out there? Earth Science Reviews, 66: 183-197.

Moridis, G., 2008. TOUGH+Hydrate v1.0 User's Manual: A Code for the Simulation of System Behavior in Hydrate-Bearing Geologic Media.

Moridis, G.J. et al., 2009. Toward Production From Gas Hydrates: Current Status, Assessment of Resources, and Simulation-Based Evaluation of Technology and Potential.

Moridis, G.J., Silpngarmlert, S., Reagan, M.T., Collett, T. and Zhang, K., Gas production from a cold, stratigraphically-bounded gas hydrate deposit at the Mount Elbert Gas Hydrate Stratigraphic Test Well, Alaska North Slope: Implications of uncertainties. Marine and Petroleum Geology, 28(2): 517-534.

Moridis, G.J. and Sloan, E.D., 2007. Gas production potential of disperse low-saturation hydrate accumulations in oceanic sediments. Energy Conversion and Management, 48(6): 1834-1849.

National Resource Council, 2004. Charting the future of methane hydrate research in the United States, 192 pp.

Rees, E.V.L., Kneafsey, T.J. and Seol, Y., 2011. Methane Hydrate Distribution from Prolonged and Repeated Formation in Natural and Compacted Sand Samples: XRay CT Observations. Journal of Geological Research, 2011: Article ID 791815, 15 pages.

Ruppel, C., Boswell, R. and Jones, E., 2008. Scientific results from Gulf of Mexico Gas Hydrates Joint Industry Project Leg 1 drilling: Introduction and overview. Marine and Petroleum Geology, 25(9): 819-829.

Ryu, B.-J. et al., 2013. Scientific results of the Second Gas Hydrate Drilling Expedition in the Ulleung Basin (UBGH2). Marine and Petroleum Geology, 47(0): 1-20.

Sloan, E.D. and Koh, C.A., 2008. Clathrate Hydrates of Natural Gases. CRC Press, Taylor and Francis Group, $721 \mathrm{pp}$.

Sloan, E.D., Subramanian, S., Matthews, P.N., Lederhos, J.P. and Khokhar, A.A., 1998. Quantifying Hydrate Formation and Kinetic Inhibition. Ind. Eng. Chem. Res., 37: 3124-3132. 
Trehu, A.M. et al., 2004. Three-dimensional distribution of gas hydrate beneath southern Hydrate Ridge: constraints from ODP Leg 204. Earth and Planetary Science Letters, 222(3-4): 845-862.

van Genuchten, M.T., 1980. A Closed-Form Equation for Predicting the Hydraulic Conductivity of Unsaturated Soils. Soil Science Society of America Journal, 44(5): 892-898.

White, M., 2008. Personal communication.

Zhang, K. and Moridis, G.J., 2008. A Domain Decomposition Approach for Large-Scale Simulations of Coupled Processes in Hydrate-Bearing Geologic Media, 6th International Conference on Gas Hydrates, Vancouver, British Columbia, Canada. 
Figure 1. top. X-ray image of experimental setup. bottom. Schematic of experimental setup. $(\mathrm{V}=$ valve, $\mathrm{T}=$ thermocouple, $\mathrm{P}=$ pressure sensor $)$

Figure 2. a. Calibrated initial CT scans showing endcaps with snowflake-shaped fluid distribution channels, hydrate in darker veins, thermocouples (small white dots), and elastomer sleeve (purple), b. CT scans after thawing the sample, c. density differences between the thawed and dissociated samples where blue indicates lower density and red indicates higher density. The scale bars in each image are in units of $\mathrm{g} / \mathrm{cm}^{3}$.

Figure 3. a. Machined PVC endpiece for fluid distribution through open grooves (black), b. Typical cross section with thermocouple in center, c. Typical cross section showing location of the confining fluid thermocouple.

Figure 4. a. X-ray CT cross-section through the frozen core. In this image, brighter colors represent higher density, and darker colors represent lower density. Two regions are clearly visible. b. grain size distributions and mineral fractions.

Figure 5. Pressures, temperatures, and differential pressure during the depressurization test.

Figure 6. Sample density and density changes over time for three locations. Left-most column shows the initial density distribution of the sample at Slices 1 (the gas outlet), 5 (near the center), and 10 (close to the far end), with brighter colors indicating higher density. In the columns to the right of that, changes in density over time are shown with 
darker blue indicating larger changes.

Figure 7. Volume of gas produced and rate of gas production during the test. Rate is the red curve, with moles of gas produced is shown by the black curve.

Figure 8. Comparison between measurements and optimized (history-matched) predictions of produced gas from the core dissociation experiment. 


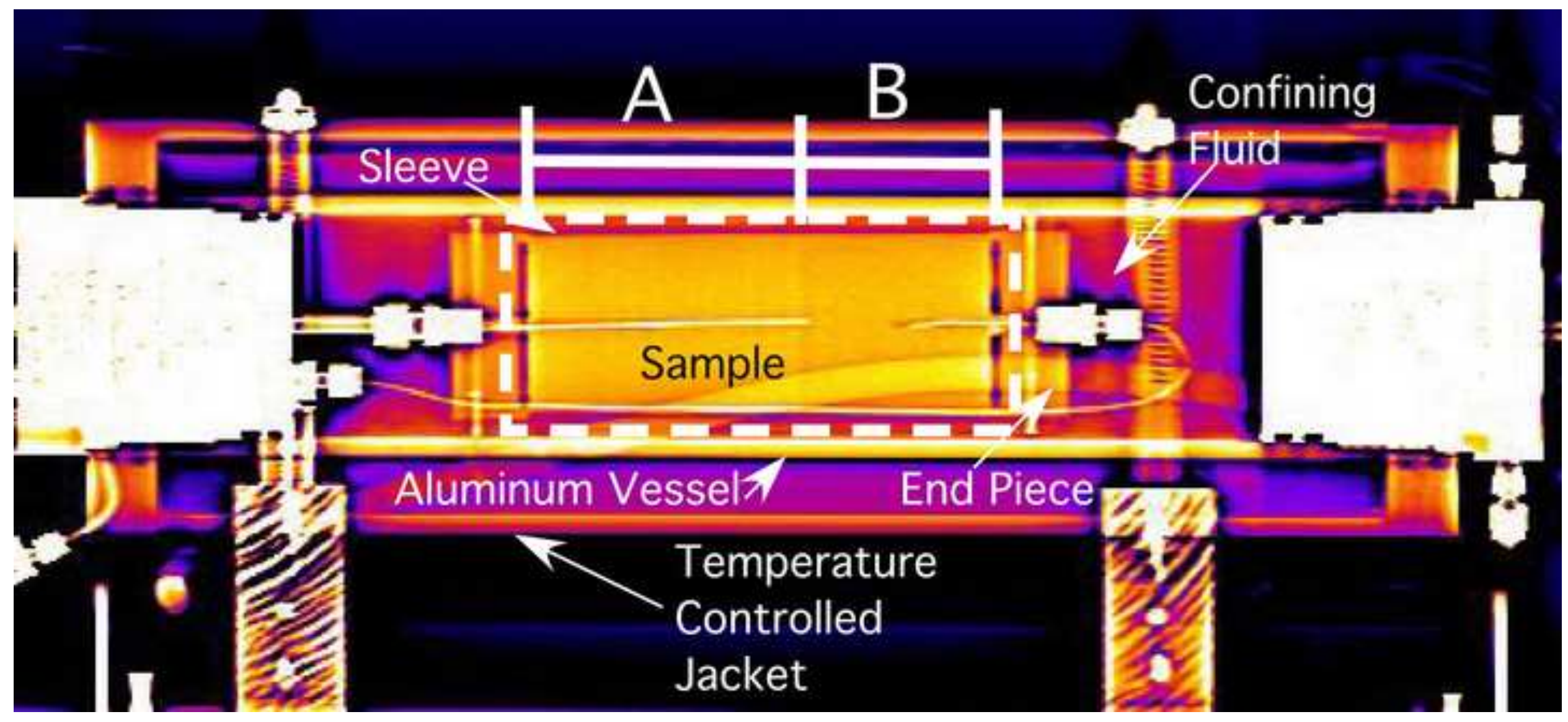




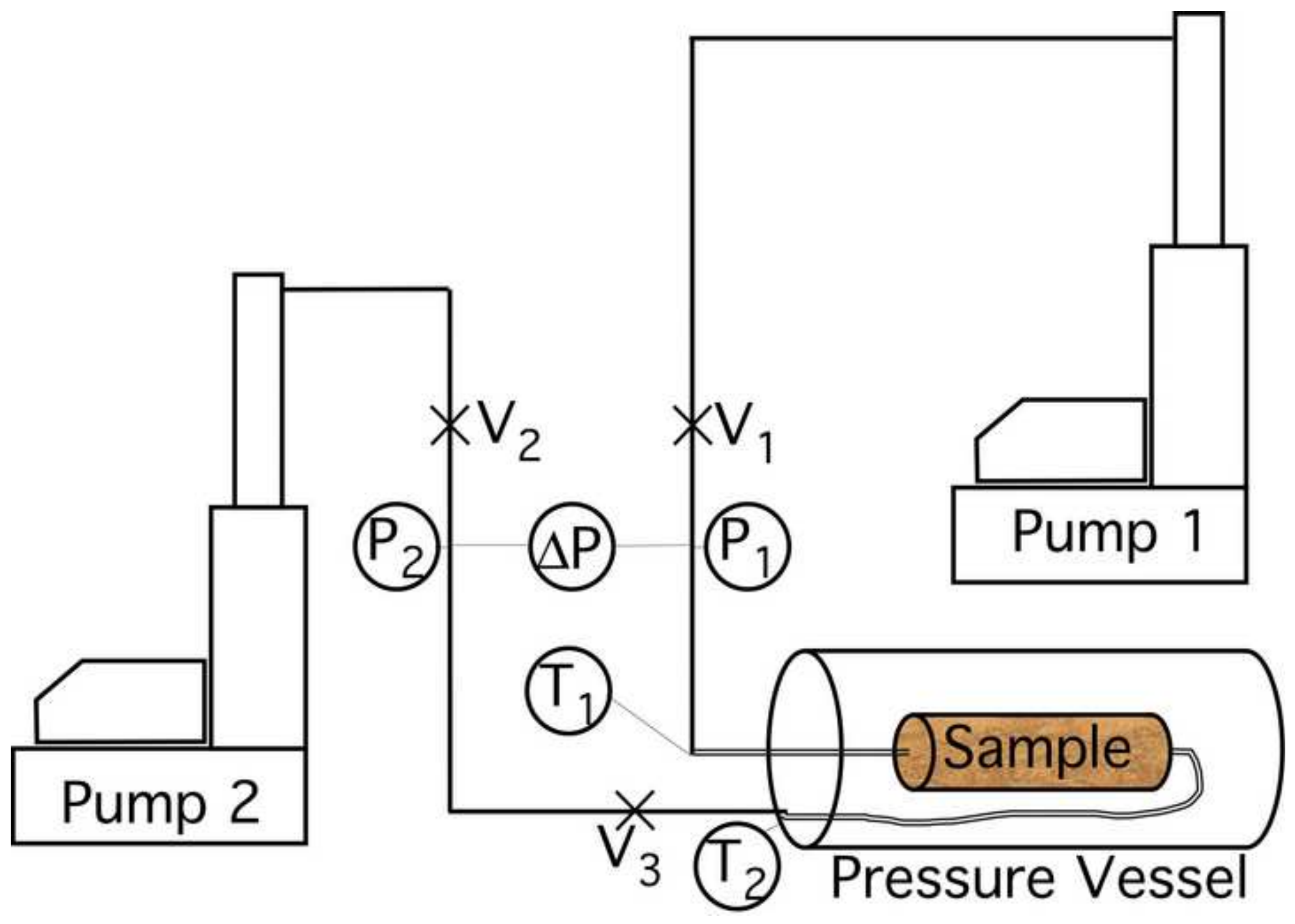




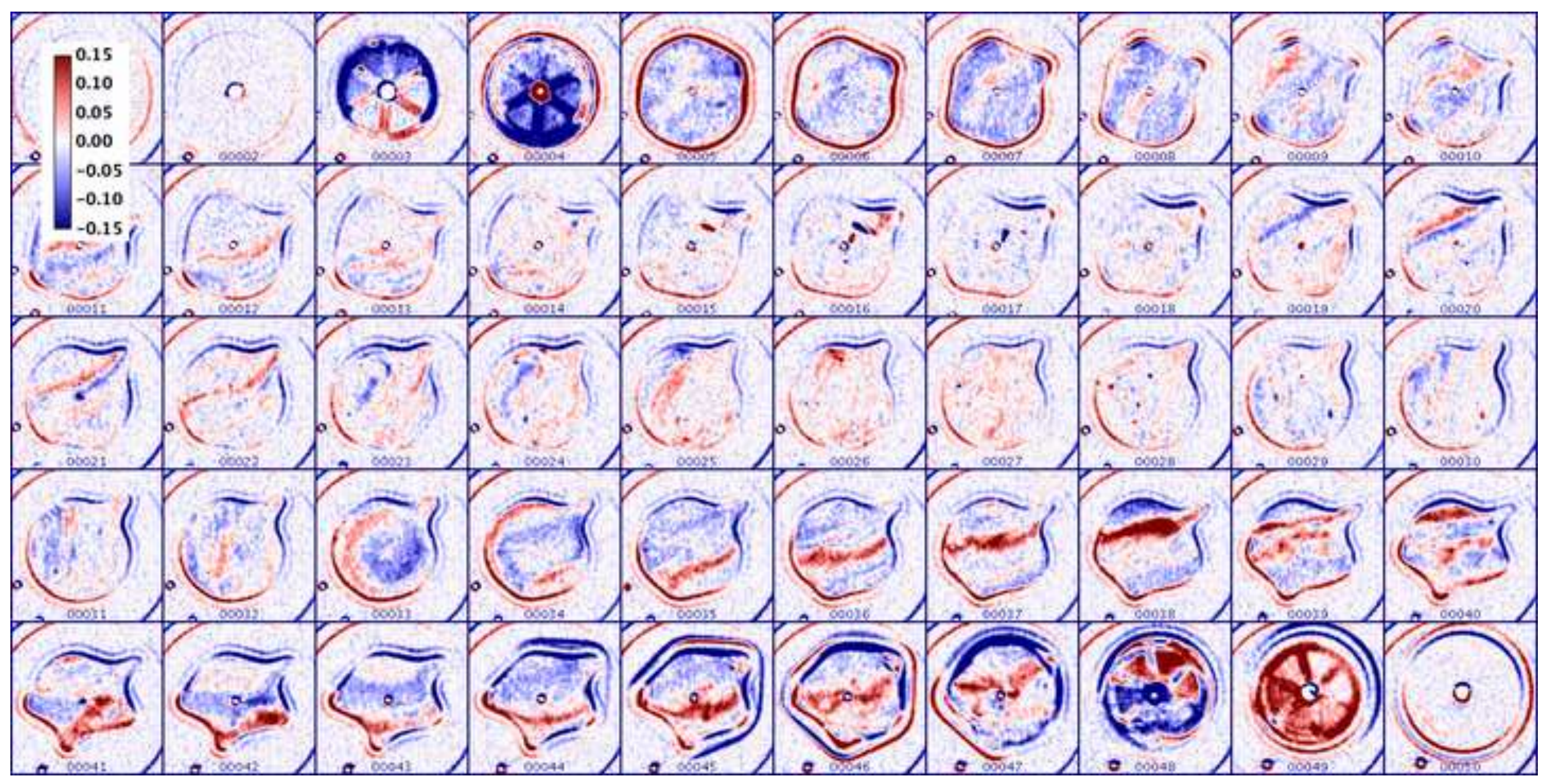



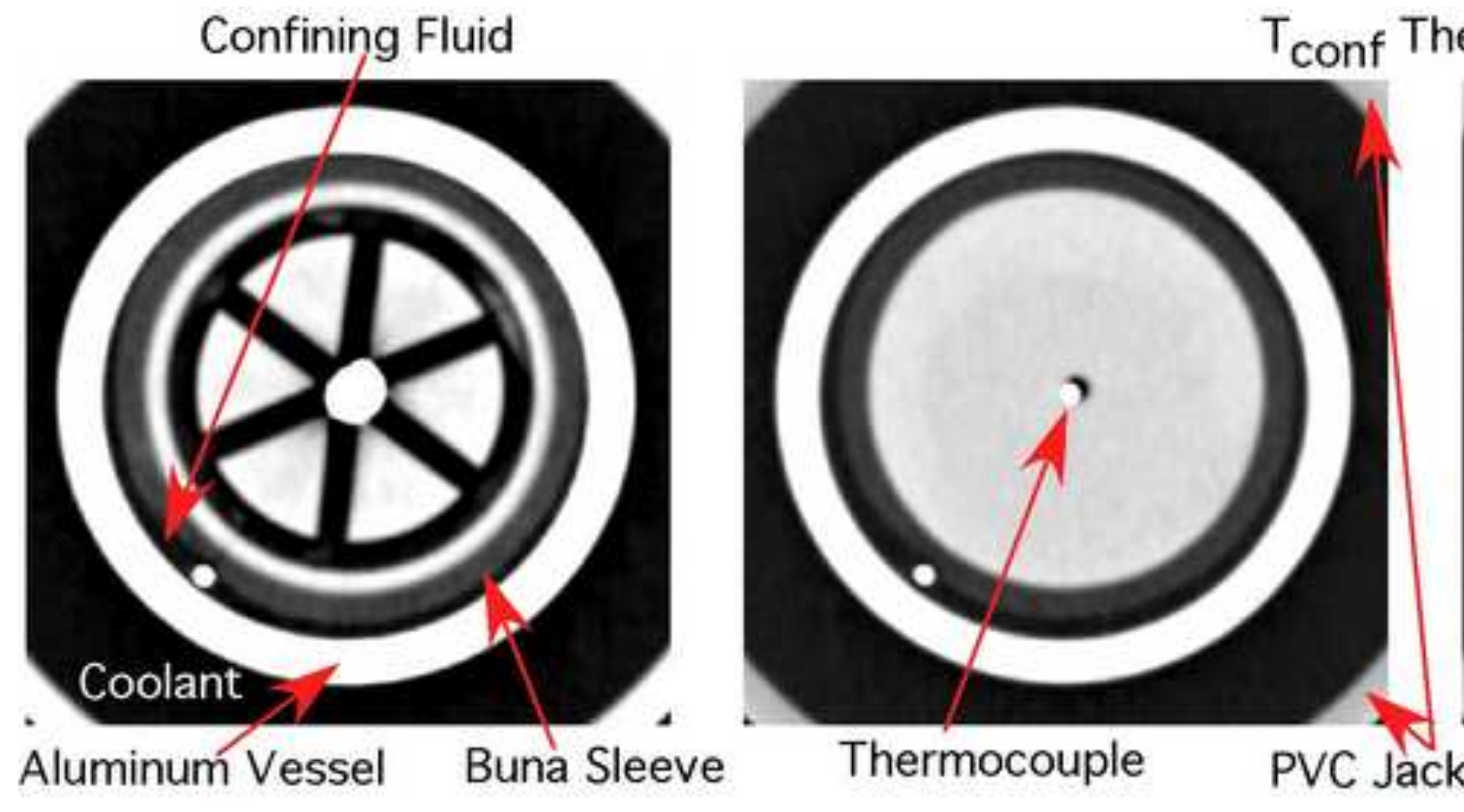

\section{hermocouple}

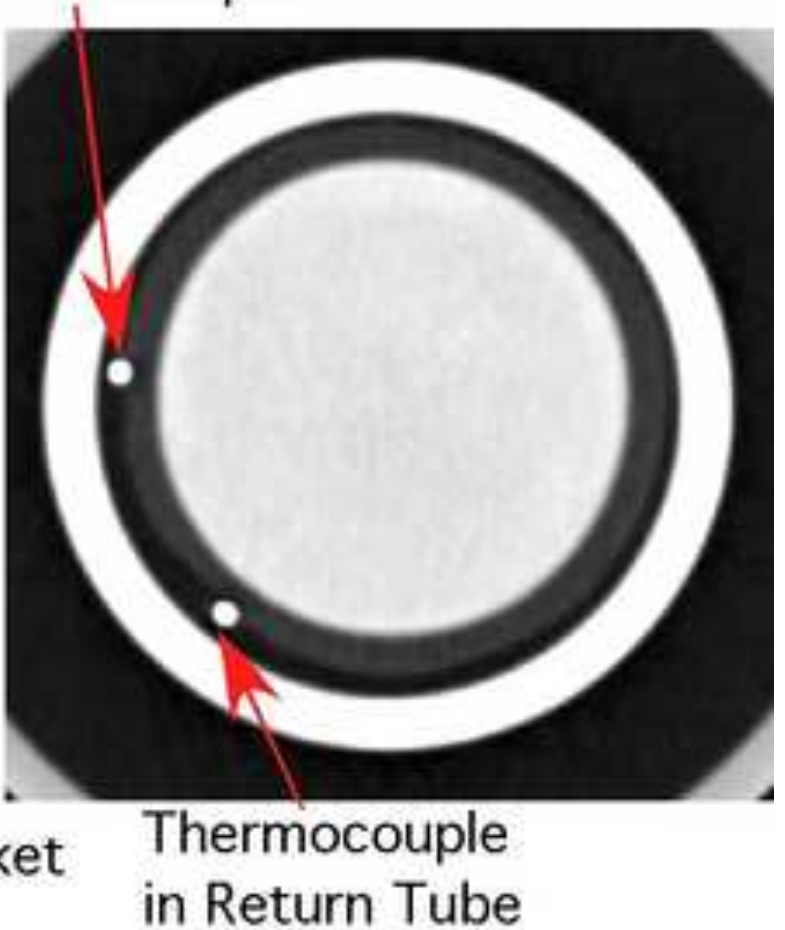

Thermocouple in Return Tube

PVC Jacket 


\section{Figure 4a \\ Figure 4}
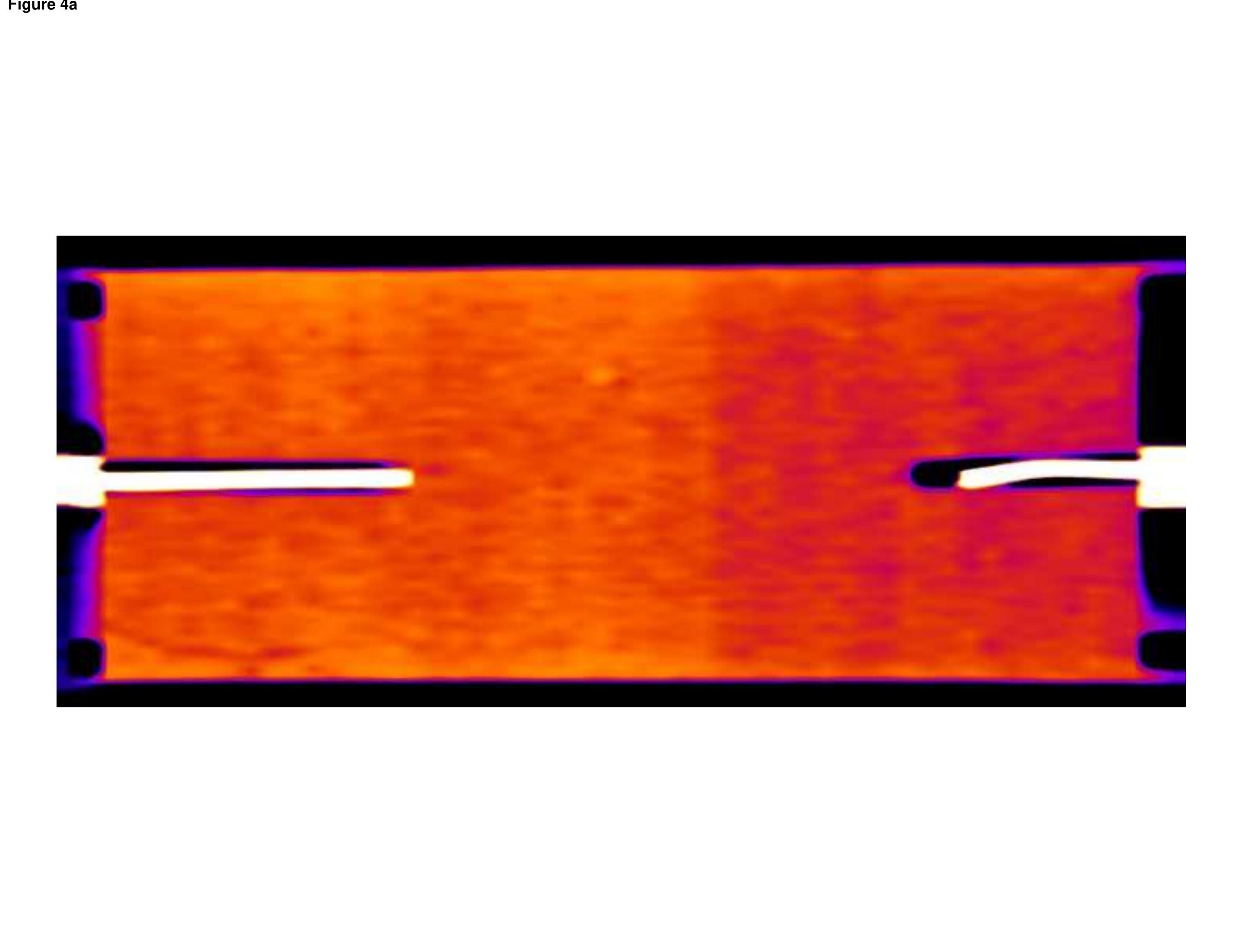

.

(

(

.

.




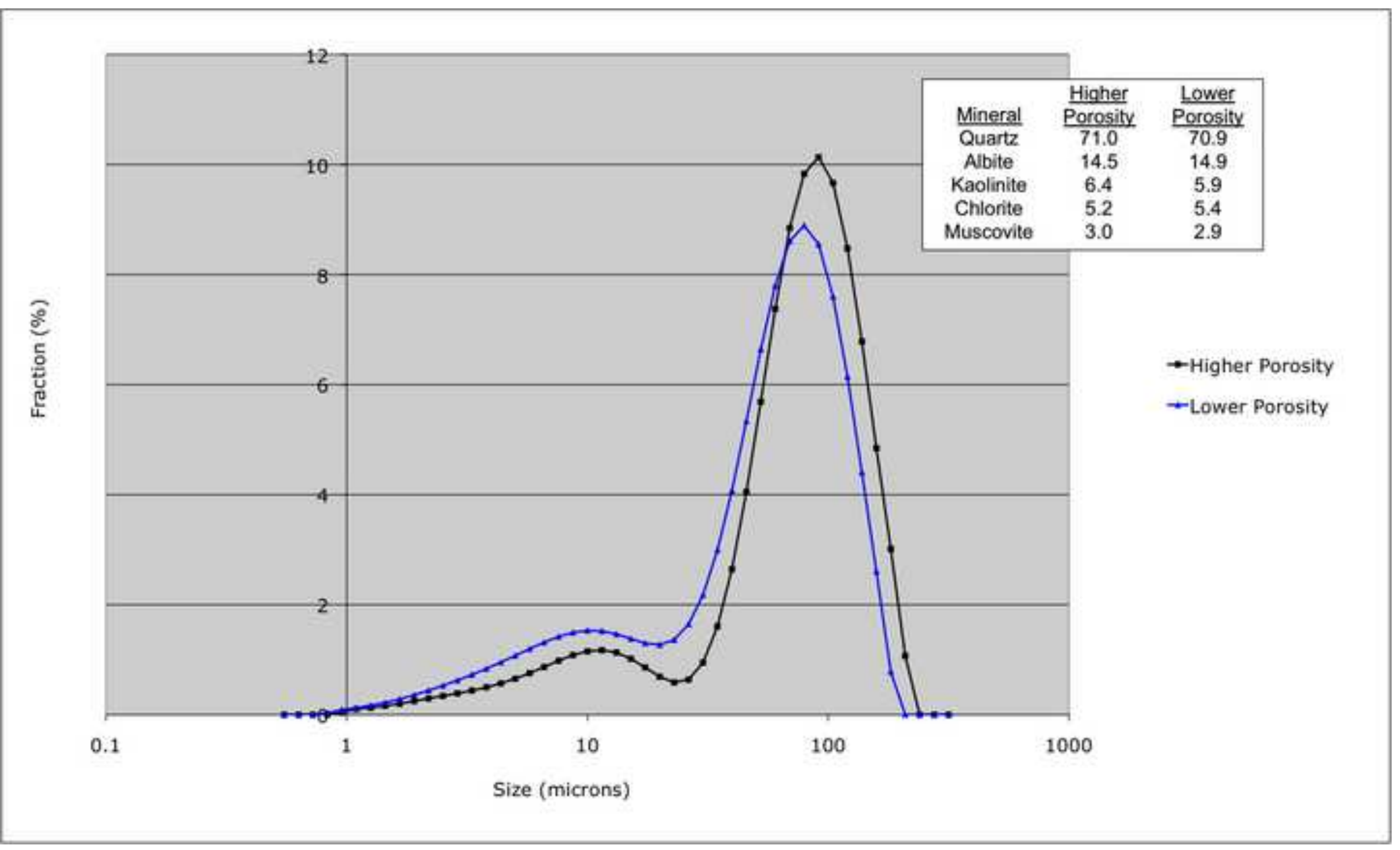




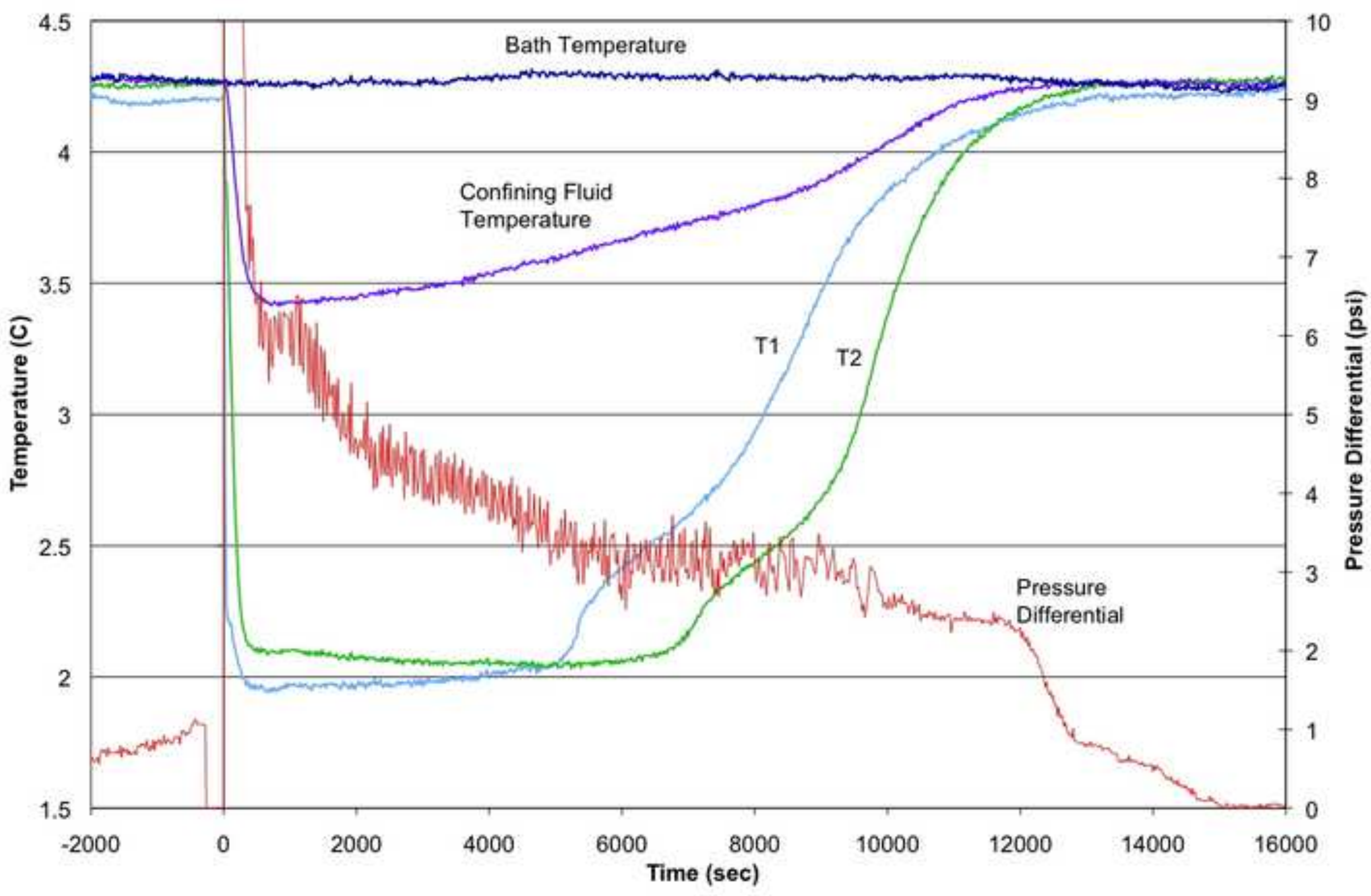




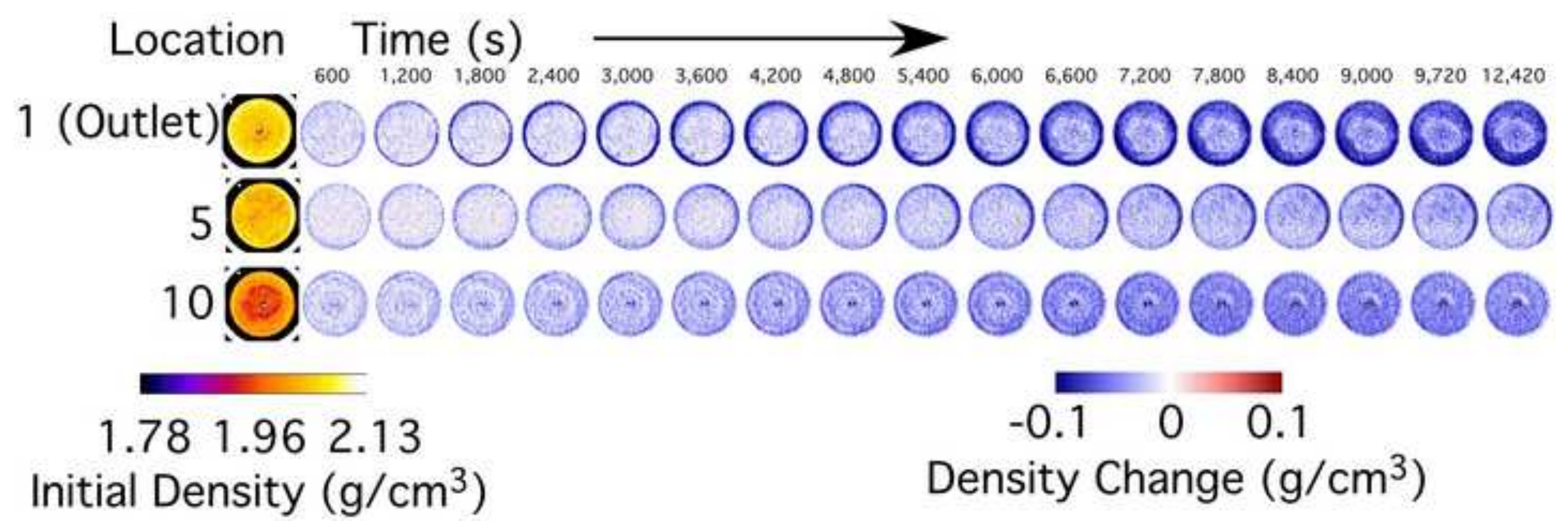




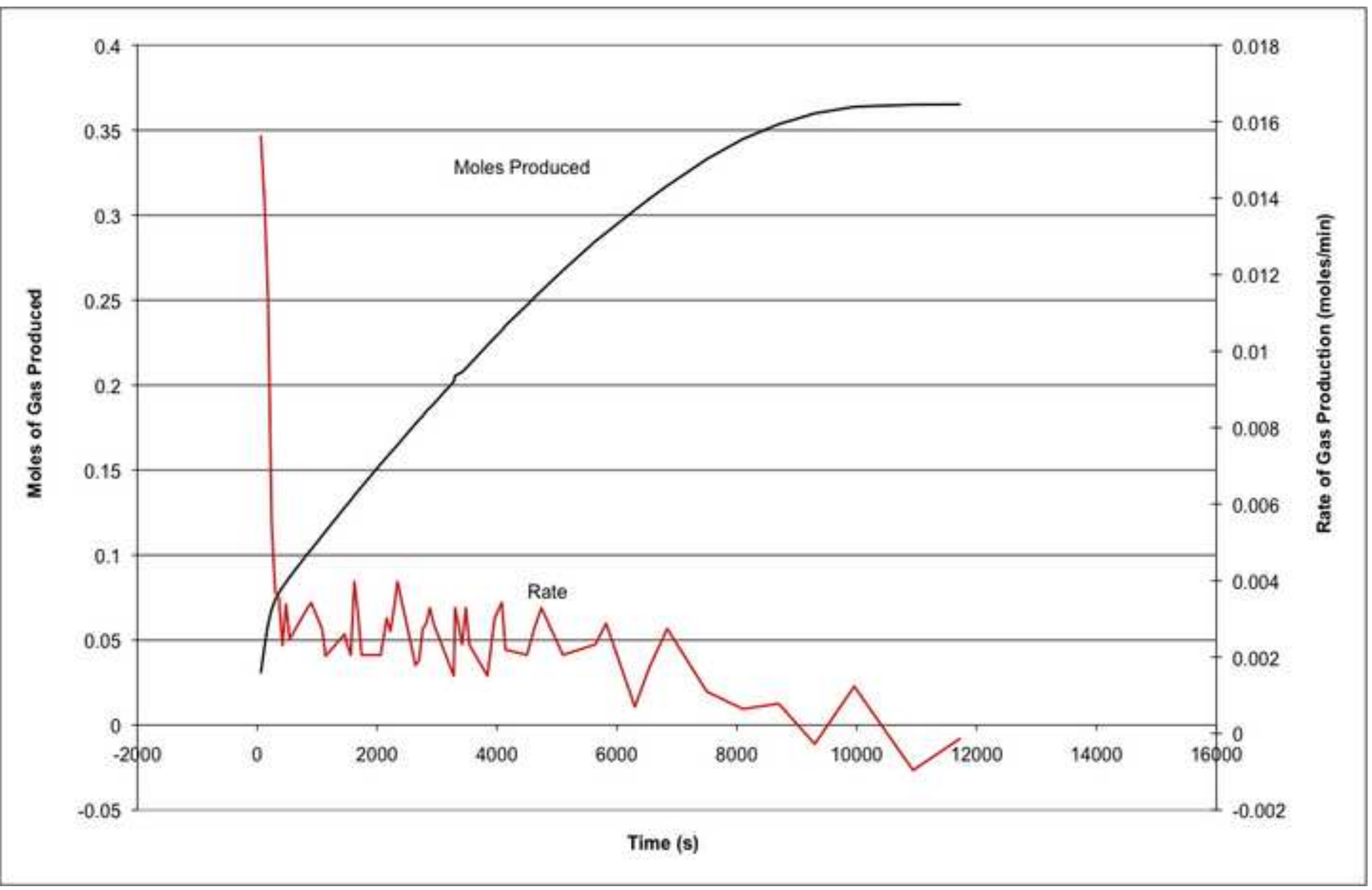


Figure 8

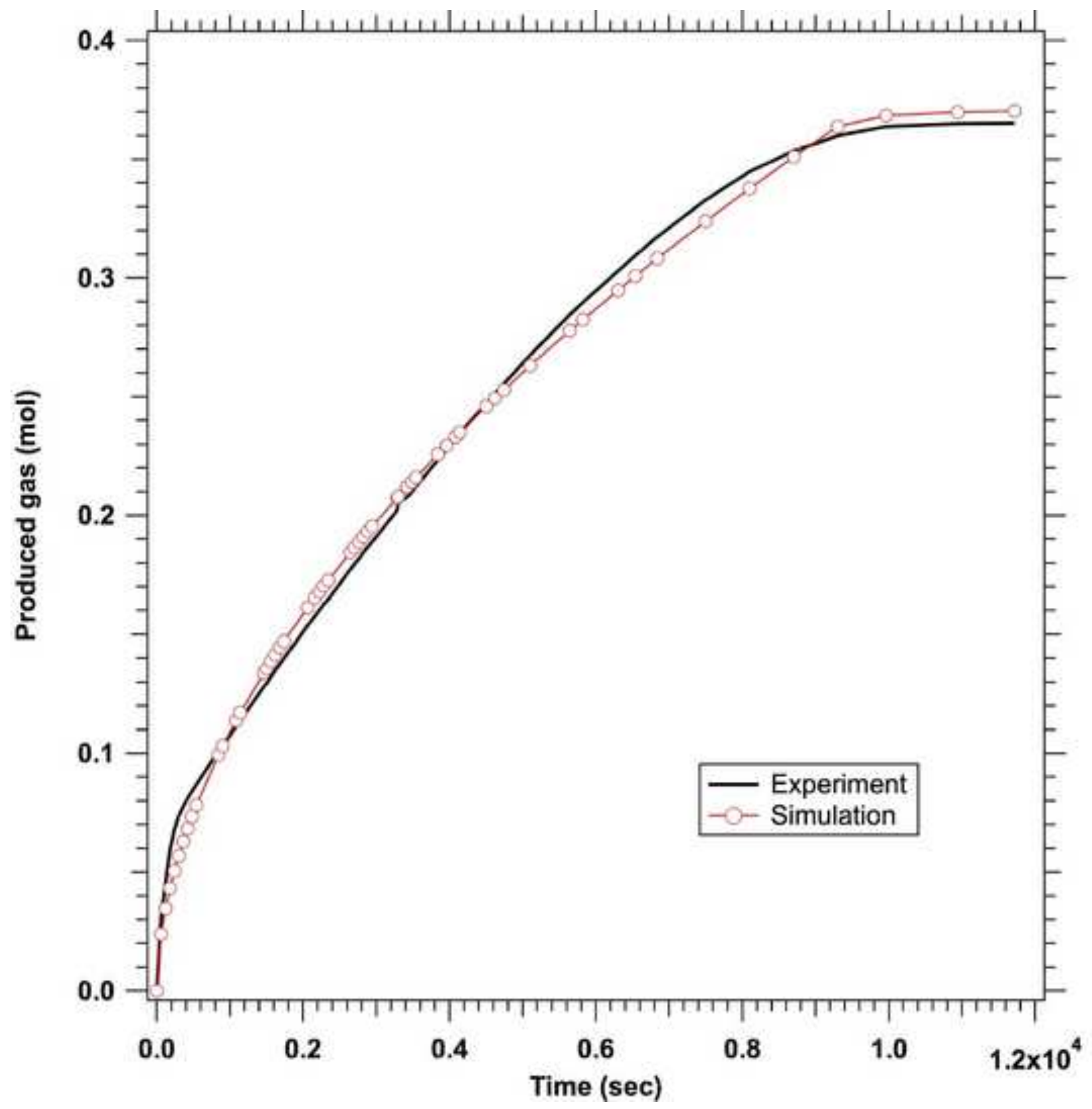


Table 1. Density distribution of selected NGHP-01 cores in $\mathrm{g} / \mathrm{cm}^{3}$. Each "circle" is a sequential slice from left to right, top to bottom.

\begin{tabular}{|c|c|c|c|}
\hline & Sample & Density distribution indicated by CT & Comments \\
\hline a. & 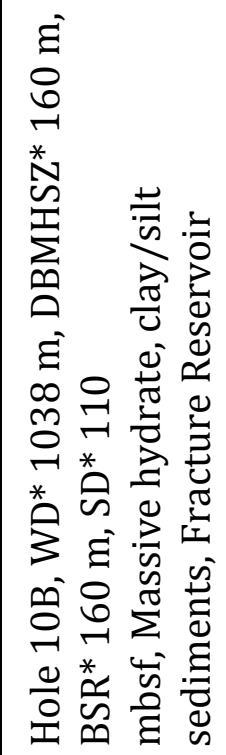 & Left arrow: example of vein. Right arrow: disturbed region. & 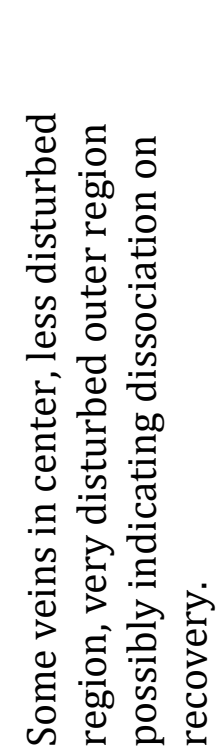 \\
\hline
\end{tabular}




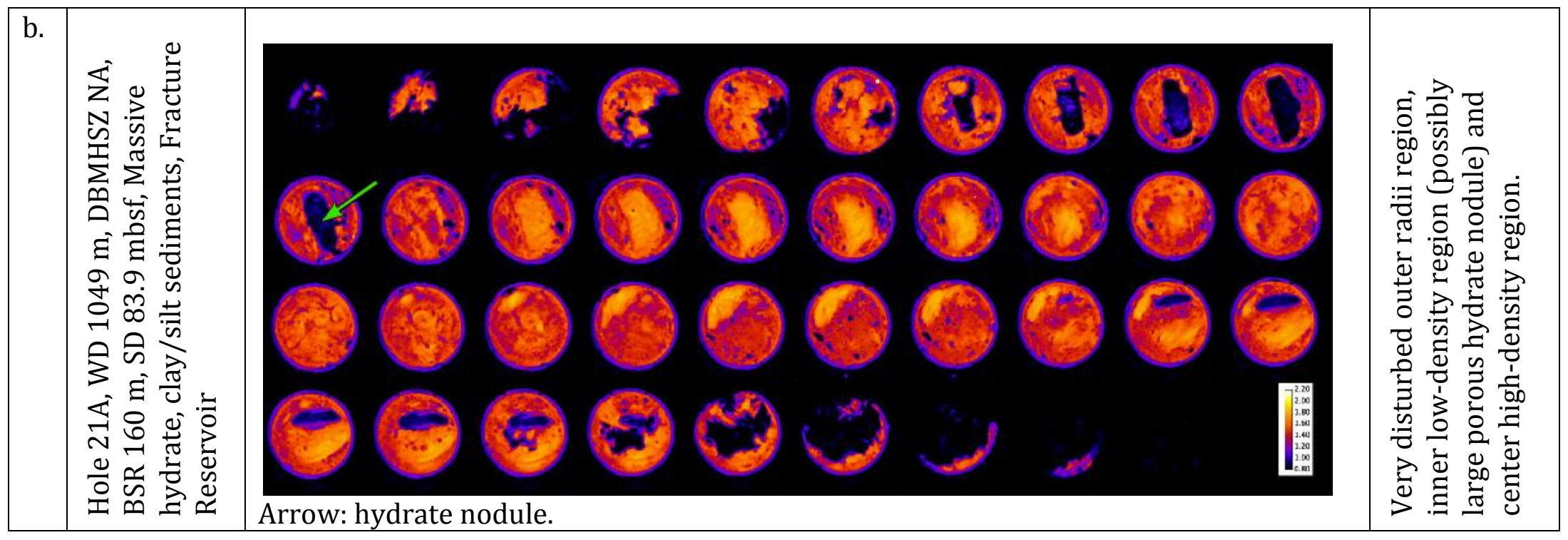




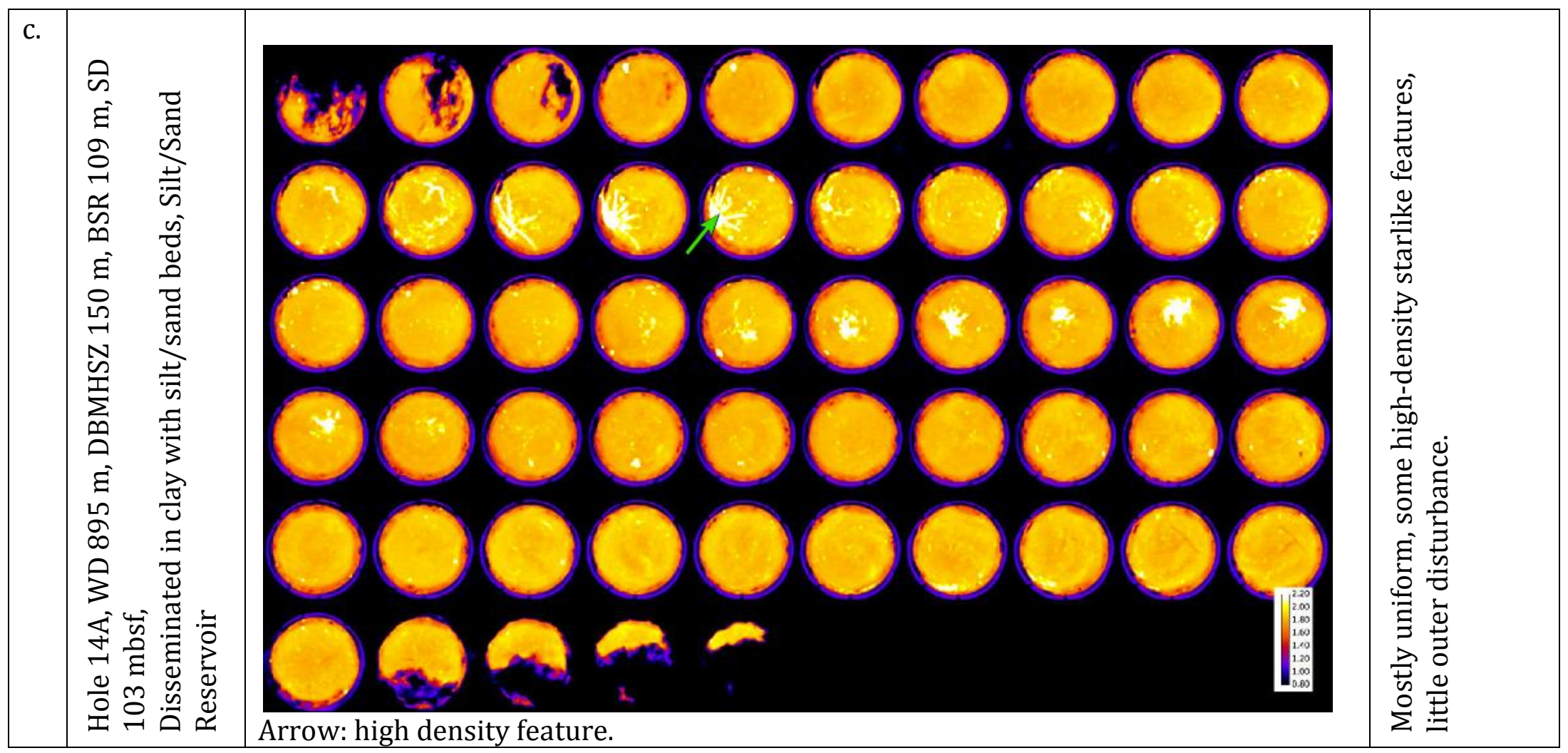




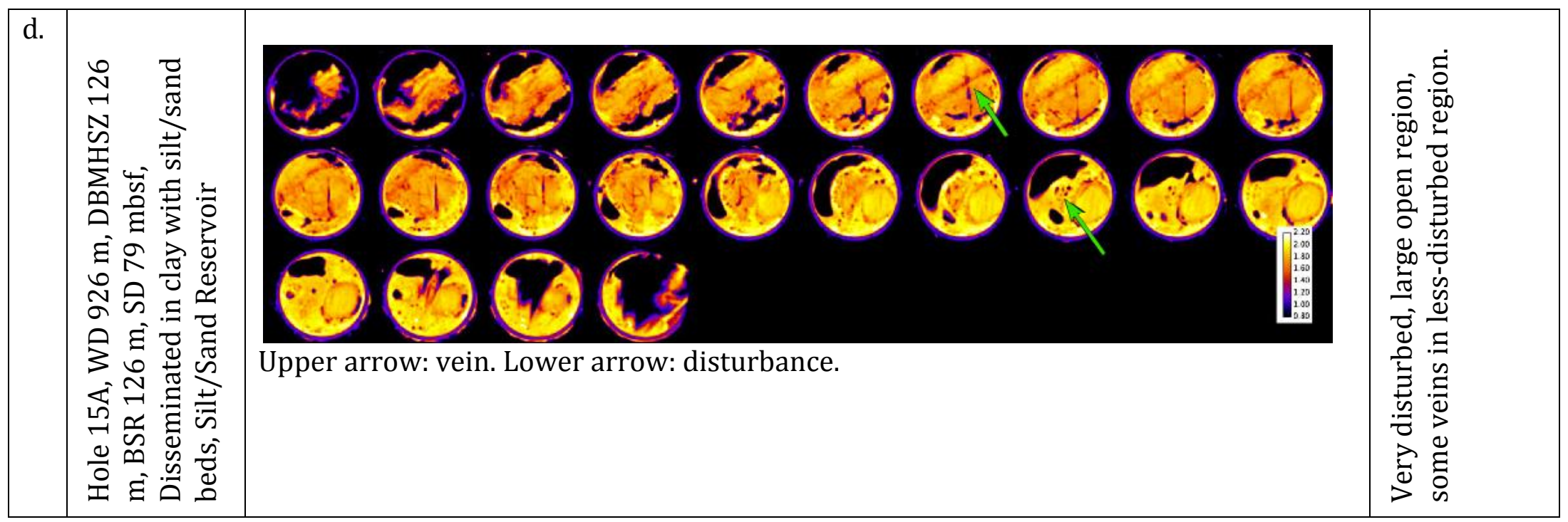




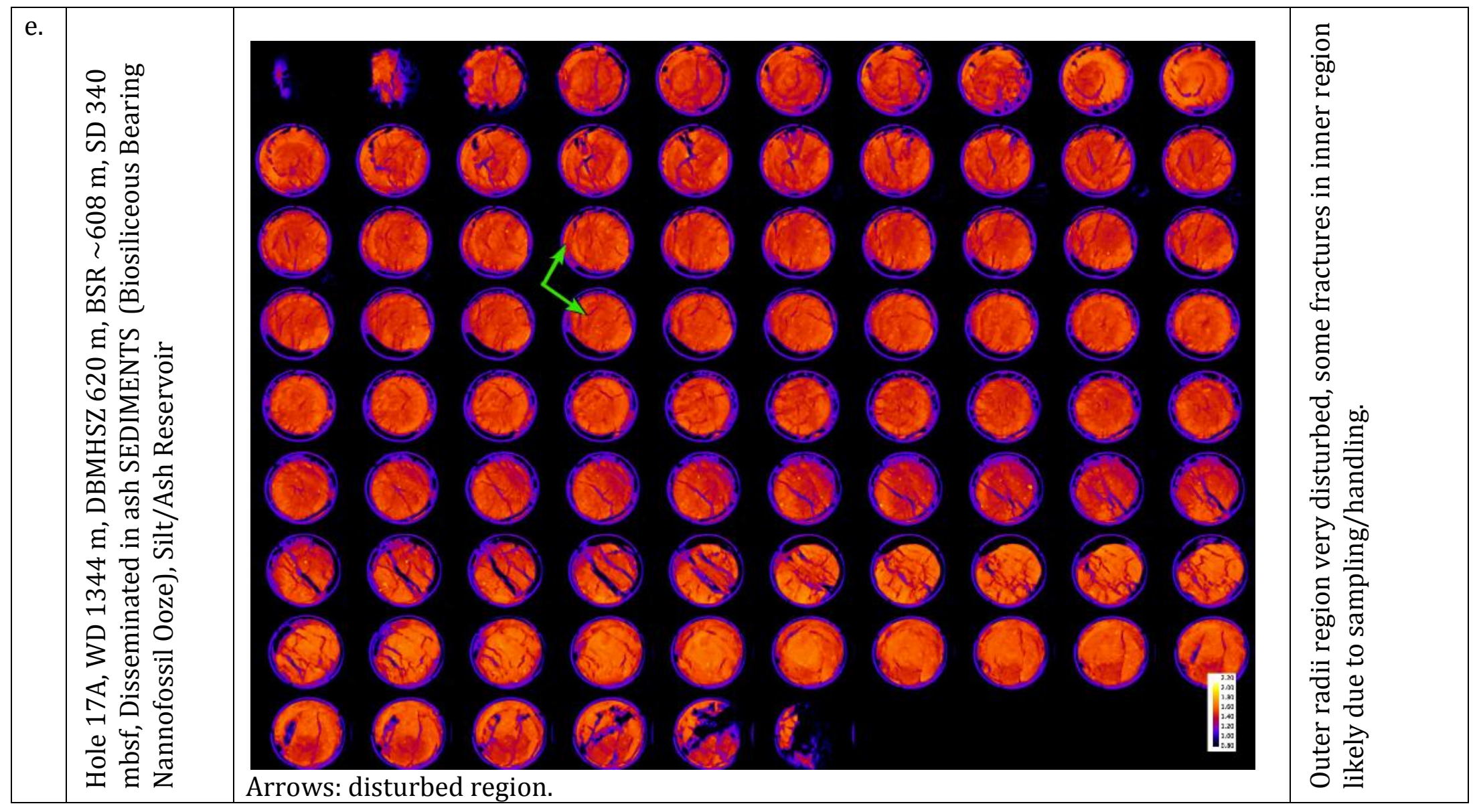




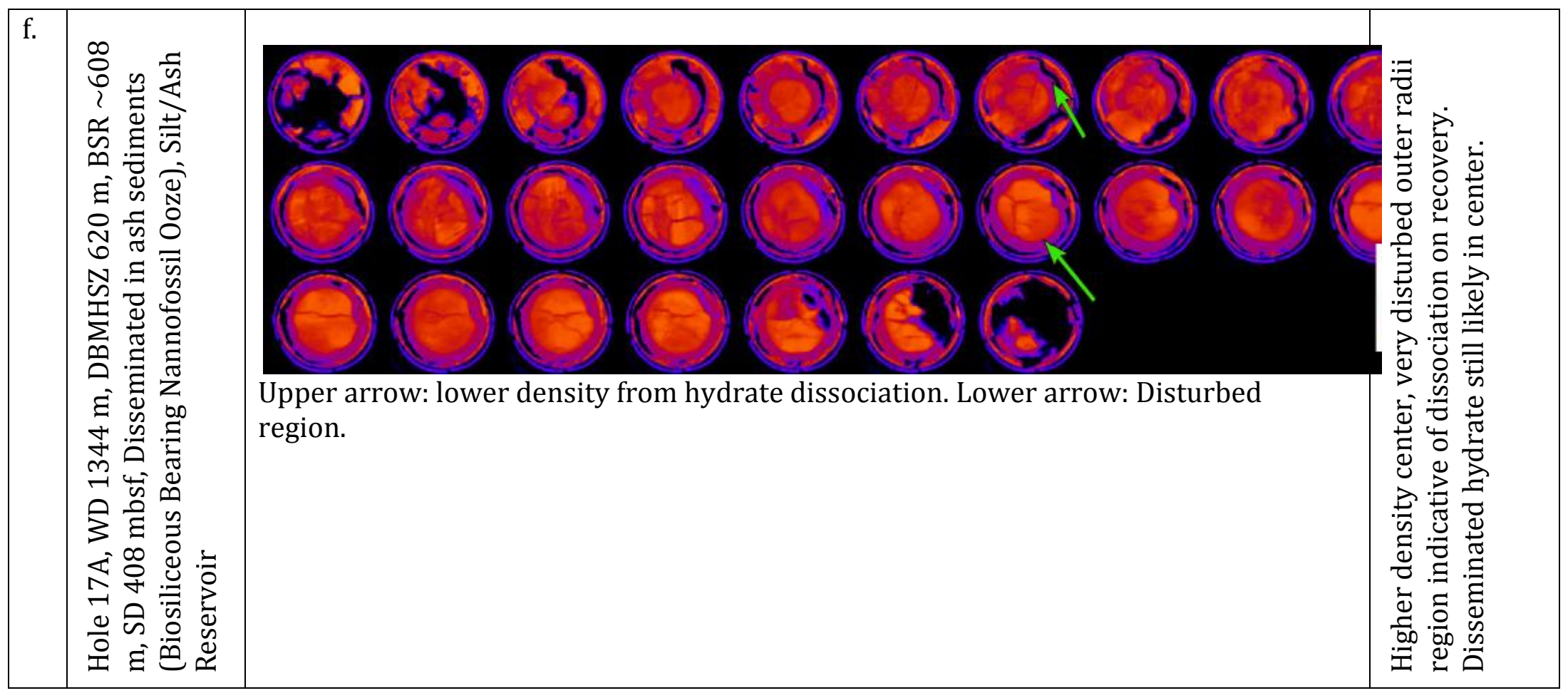




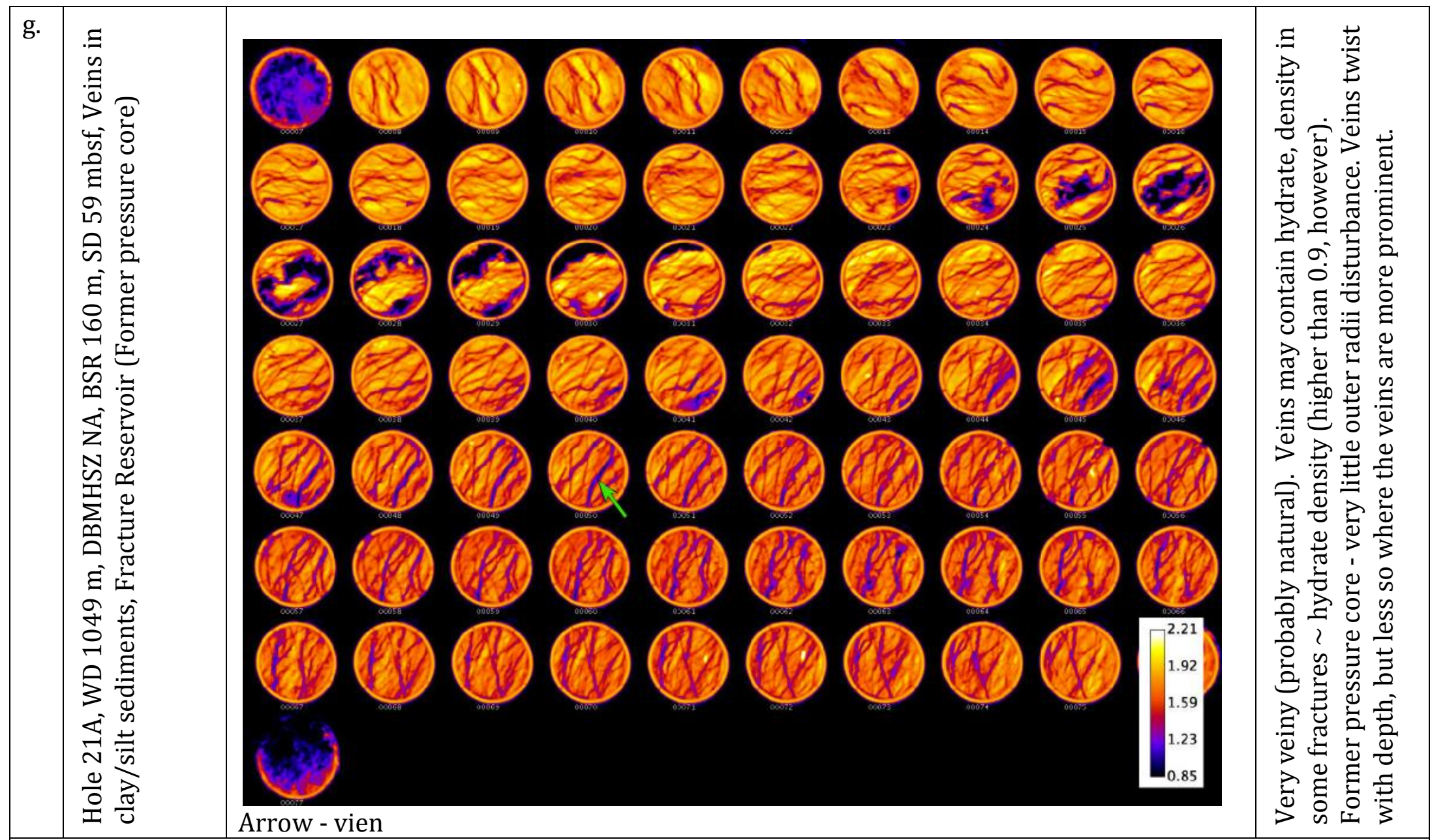

*WD - Water Depth, DBMHSZ - Depth to the Base of the Methane Hydrate Stability Zone, BSR - Bottom Simulating Reflector Depth, SD - Sample Depth 
Table 2. Properties of the two regions of the core

\begin{tabular}{|l|l|l|}
\hline & $\begin{array}{l}\text { Region A (left in Figures 2, } \\
\text { 4) }\end{array}$ & $\begin{array}{l}\text { Region B (right in Figures } \\
2,4)\end{array}$ \\
\hline Average Porosity (from CT) & .337 & .353 \\
\hline $\begin{array}{l}\text { Approximate Hydrate } \\
\text { Saturation (as received) }\end{array}$ & .23 & .42 \\
\hline
\end{tabular}


Table 3. Hydrate Deposit Properties in Unit D, Mount Elbert Site

\begin{tabular}{|c|c|}
\hline Parameter & Value \\
\hline Gas composition & $100 \% \mathrm{CH}_{4}$ \\
\hline Medium compressibility of HBL & $5 \times 10^{-9} \mathrm{~Pa}^{-1}$ \\
\hline Intrinsic permeability $k_{x}=k_{y}=k_{z}$ & $10^{-12} \mathrm{~m}^{2}(=1 \mathrm{D})$ \\
\hline Grain density $\rho_{R}$ & $2750 \mathrm{~kg} / \mathrm{m}^{3}$ \\
\hline Dry thermal conductivity $\left(k_{\Theta R D}\right)$ & $0.5 \mathrm{~W} / \mathrm{m} / \mathrm{K}$ \\
\hline Wet thermal conductivity $\left(k_{\Theta R W}\right)$ & $3.1 \mathrm{~W} / \mathrm{m} / \mathrm{K}$ \\
\hline Medium specific heat $\left(C_{\Theta}\right)$ & $1000 \mathrm{~J} / \mathrm{kg} / \mathrm{K}$ \\
\hline Aluminum 6061-T6 density & $2700 \mathrm{~kg} / \mathrm{m}^{3}$ \\
\hline $\begin{array}{l}\text { Alum. 6061-T6 thermal conductivity } \\
\left(k_{\Theta}\right)\end{array}$ & $155 \mathrm{~W} / \mathrm{m} / \mathrm{K}$ \\
\hline Alum. 6061-T6 specific heat $\left(C_{\Theta}\right)$ & $1000 \mathrm{~J} / \mathrm{kg} / \mathrm{K}$ \\
\hline Buna rubber density & $860 \mathrm{~kg} / \mathrm{m}^{3}$ \\
\hline Buna thermal conductivity $\left(k_{\Theta}\right)$ & $0.3 \mathrm{~W} / \mathrm{m} / \mathrm{K}$ \\
\hline Buna specific heat $\left(C_{\Theta}\right)$ & $2800 \mathrm{~J} / \mathrm{kg} / \mathrm{K}$ \\
\hline PVC density & $1220 \mathrm{~kg} / \mathrm{m}^{3}$ \\
\hline PVC thermal conductivity $\left(k_{\Theta}\right)$ & $0.15 \mathrm{~W} / \mathrm{m} / \mathrm{K}$ \\
\hline PVC specific heat $\left(C_{\Theta}\right)$ & $880 \mathrm{~J} / \mathrm{kg} / \mathrm{K}$ \\
\hline $\begin{array}{l}\text { Composite thermal conductivity } \\
\text { model (Moridis et al., 2008) }\end{array}$ & $\begin{array}{l}k_{\Theta C}=k_{\Theta R D} \\
\quad+\left(S_{A}{ }^{1 / 2}+S_{H}^{1 / 2}\right) \quad\left(k_{Q R W}-k_{Q R D}\right)+ \\
\phi S_{I} k_{\Theta I}\end{array}$ \\
\hline $\begin{array}{l}\text { Capillary pressure model } \\
\text { (vanGenuchten, 1980) }\end{array}$ & $\begin{array}{l}P_{\text {capp }}=-P_{0}\left[\left(S^{*}\right)^{-1 / \lambda}-1\right]^{-\lambda} \\
S^{*}=\frac{\left(S_{A}-S_{\text {ist }}\right)}{\left(S_{\text {nudA }}-S_{\text {irA }}\right)}\end{array}$ \\
\hline$S_{i r A}$ & 1 \\
\hline$\lambda$ (White, 2008) & 0.77437 \\
\hline$P_{0}$ (White, 2008) & $5 \times 10^{3} \mathrm{~Pa}$ \\
\hline $\begin{array}{l}\text { Relative permeability model } \\
\text { (Moridis et al., 2008) }\end{array}$ & $\begin{array}{l}k_{r A}=\left(S_{A} *\right)^{n} \\
k_{r G}=\left(S_{G} *\right)^{m} \\
S_{A}^{*}=\left(S_{A}-S_{i r A}\right) /\left(1-S_{i r A}\right) \\
S_{G} *=\left(S_{G}-S_{i r G}\right) /\left(1-S_{i r A}\right) \\
\text { EPM model }\end{array}$ \\
\hline$n ; m$ (from Anderson et al., 2008) & $4.2 ; 2.5$ \\
\hline$S_{i r G}$ & 0.02 \\
\hline
\end{tabular}




\begin{tabular}{|l|l|}
\hline$S_{\text {irA }}$ & 0.20 \\
\hline
\end{tabular}



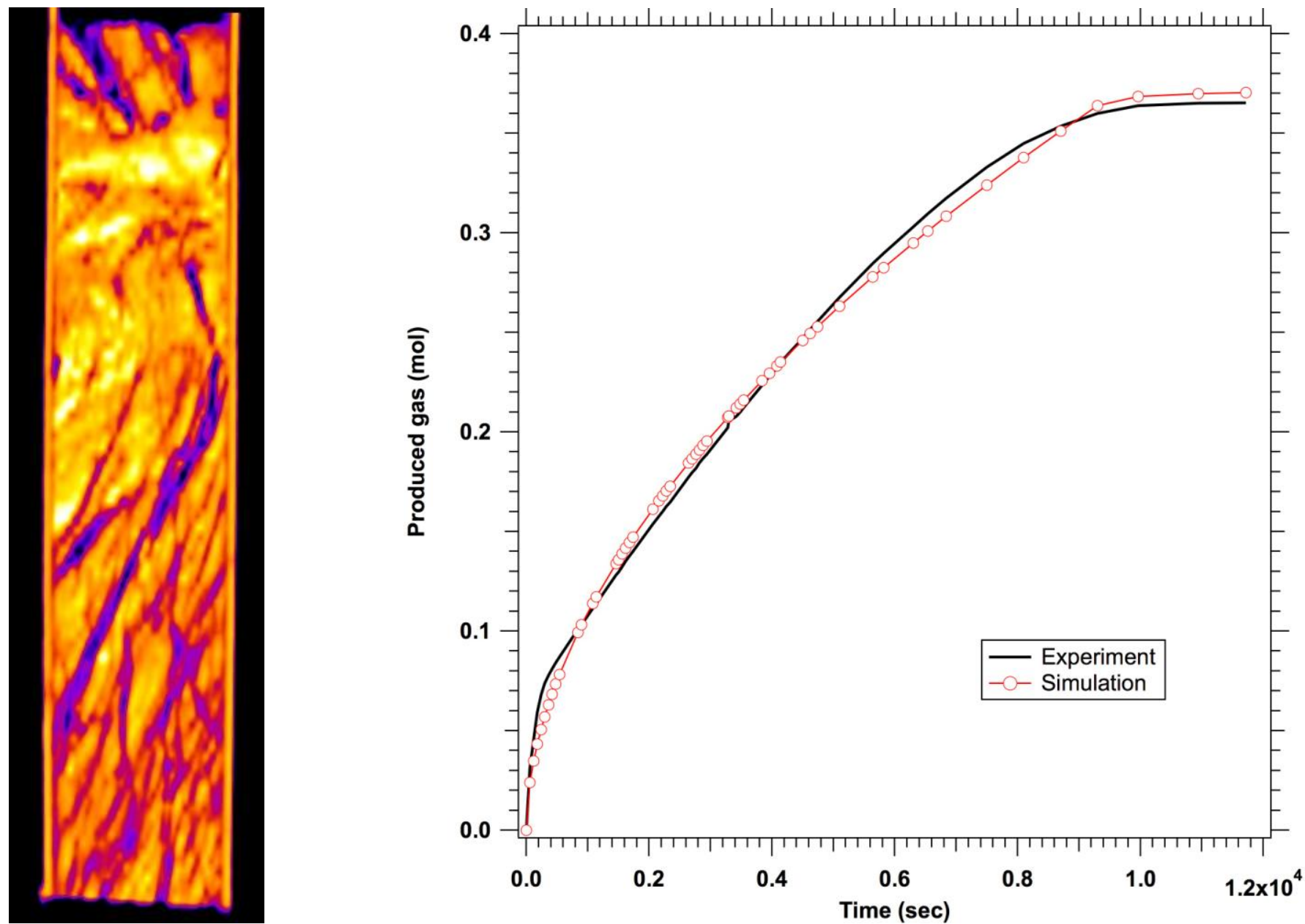

Low density (likely methane hydrate-filled) veins from NGHP-01 core, Measured and modeled gas production curves from Mount Elbert sample 